\title{
EVA - Don't Leave Earth Without It
}

J. Scott Cupples and Stephen A. Smith

NASA Johnson Space Center EVA Office and NASA Johnson Space Center Engineering Directorate

\section{Abstract}

Modern manned space programs come in two categories: those that need Extravehicular Activity (EVA) and those that will need EVA. This paper discusses major milestones in the Shuttle Program where EVA was used to save payloads, enhance on-orbit capabilities, and build structures in order to ensure success of National Aeronautics and Space Administration (NASA) missions. In conjunction, the Extravehicular Mobility Unit's (EMU) design, and hence, its capabilities evolved as its mission evolved. It is the intent that lessons can be drawn from these case studies so that EVA compatibility is designed into future vehicles and payloads.

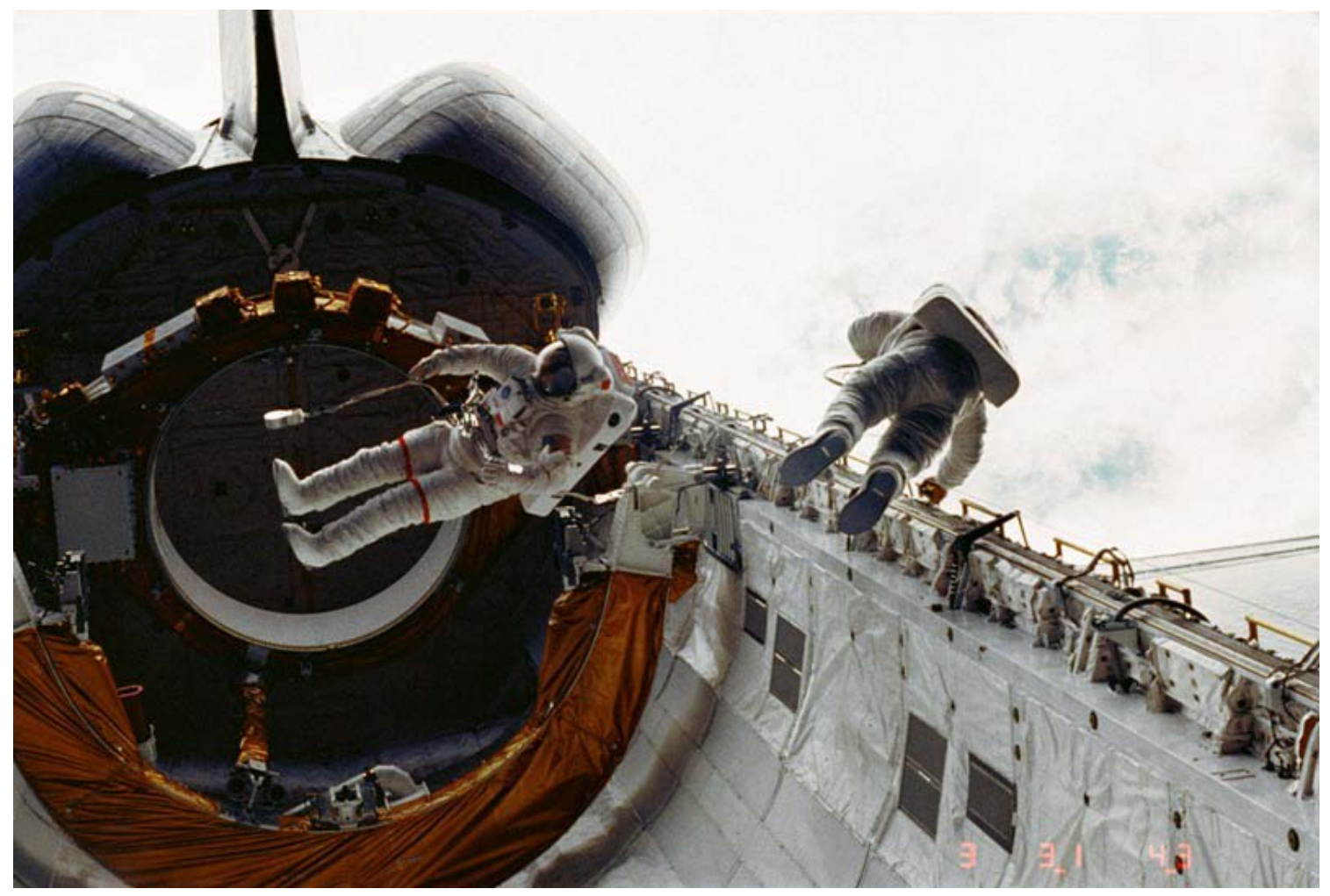

Figure 1 STS-6 First Space Shuttle EVA with newly designed Extra-Vehicular Mobility Units (EMU) 
Five EVA categories in the Shuttle Program

EVAs in the Space Shuttle Program fall into five distinct categories, the first four of which will be discussed here. The first type of EVA is the satellite repair and rescue mission. The second EVA category - and this is really a sub-category of the first - is Hubble Space Telescope (HST) repair and upgrade. Another class of EVA is dedicated to International Space Station (ISS) construction. Group four is Space Shuttle and Space Station repair and maintenance. This group includes EVAs performed on Shuttle, ISS and the Russian space station, Mir. The last group is developmental EVAs, which were designed to test new EVA techniques, test the performance of various EVA tools and the EMU, and to study the expected EVA environment for ISS.

\section{Satellite Repair and Rescue}

The early years of Shuttle Program EVAs focused on satellite repair and rescue thanks to the new capability to access satellites, work on them in the safety of the Shuttle Payload Bay, and bring payloads back to Earth. Between 1983 and 1997, NASA conducted 13 EVAs over eight missions to capture, repair, and redeploy satellites. These early EVAs allowed NASA to revive hardware that would have otherwise been space junk; moreover, it saved taxpayers, corporations and investors millions of dollars.

The initial EVA satellite rescue missions required flying the Manned Maneuvering Unit (MMU) out to the afflicted satellite, capturing it, and flying it back to the Shuttle. On Shuttle mission STS-41C in April 1984, EVA crewmembers retrieved the Solar Maximum satellite and brought it back to the Orbiter, where it was berthed, repaired and redeployed by Shuttle crewmembers. This was the first satellite repair mission of its kind. It was followed in November by STS-51A, during which the EVA crew flew the MMU to two different satellites, Palapa B-2 and Westar IV, and berthed them in the Shuttle for return to Earth. Once on the ground, the satellites were refurbished and re-launched to orbit. 


\section{EVA - Don't Leave Earth Without It}

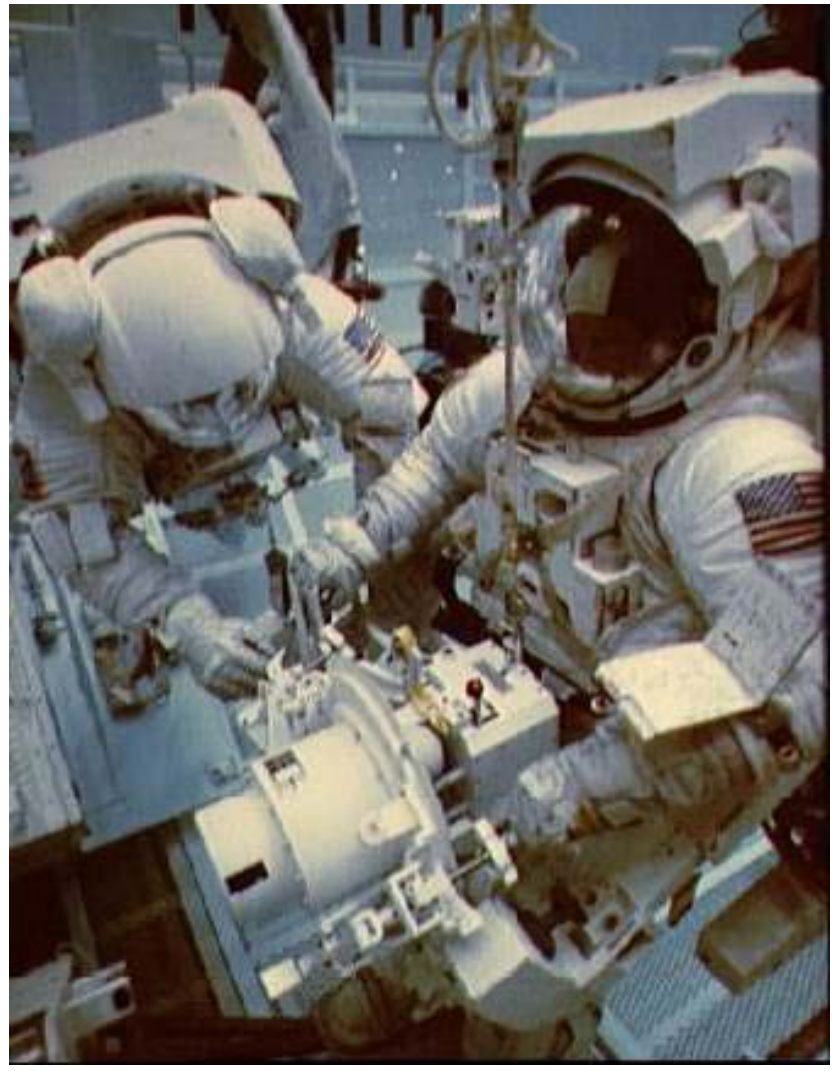

Figure 2 STS-41C Training with MMU at the Weightless Environmental Training Facility (WETF)

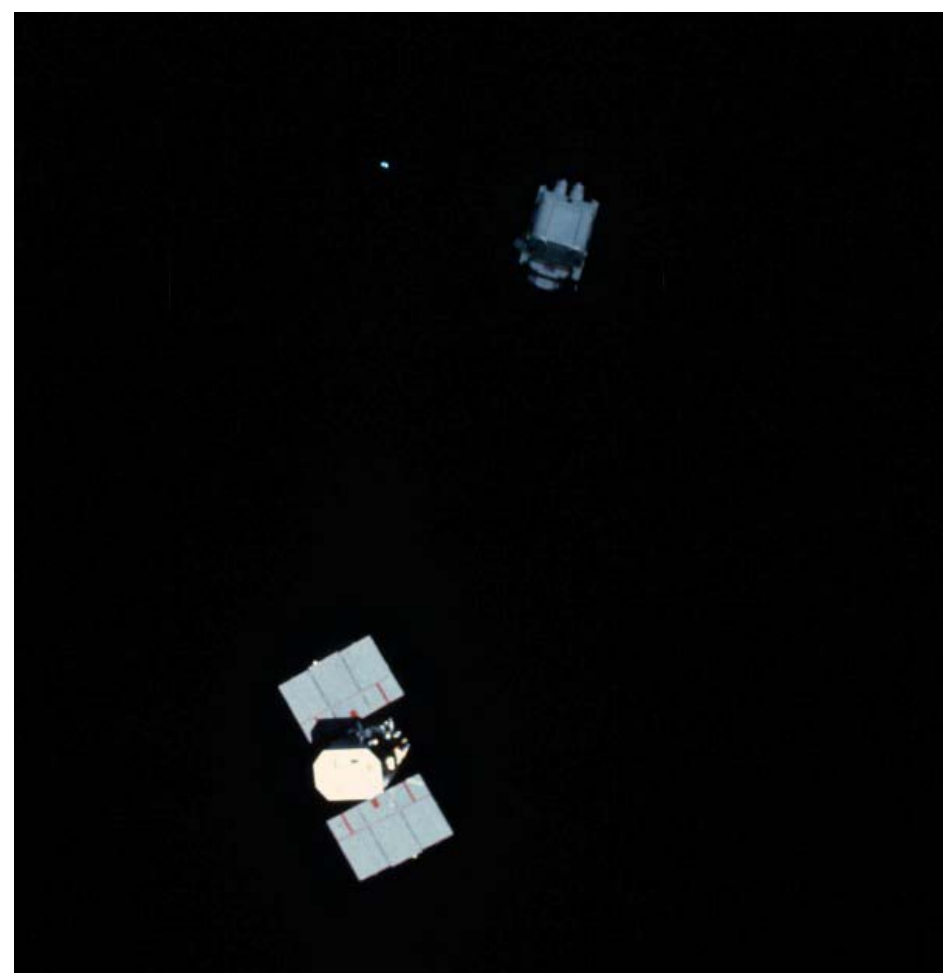

Figure 3 STS-41C MMU rendezvous with Solar Max 
EVA - Don't Leave Earth Without It

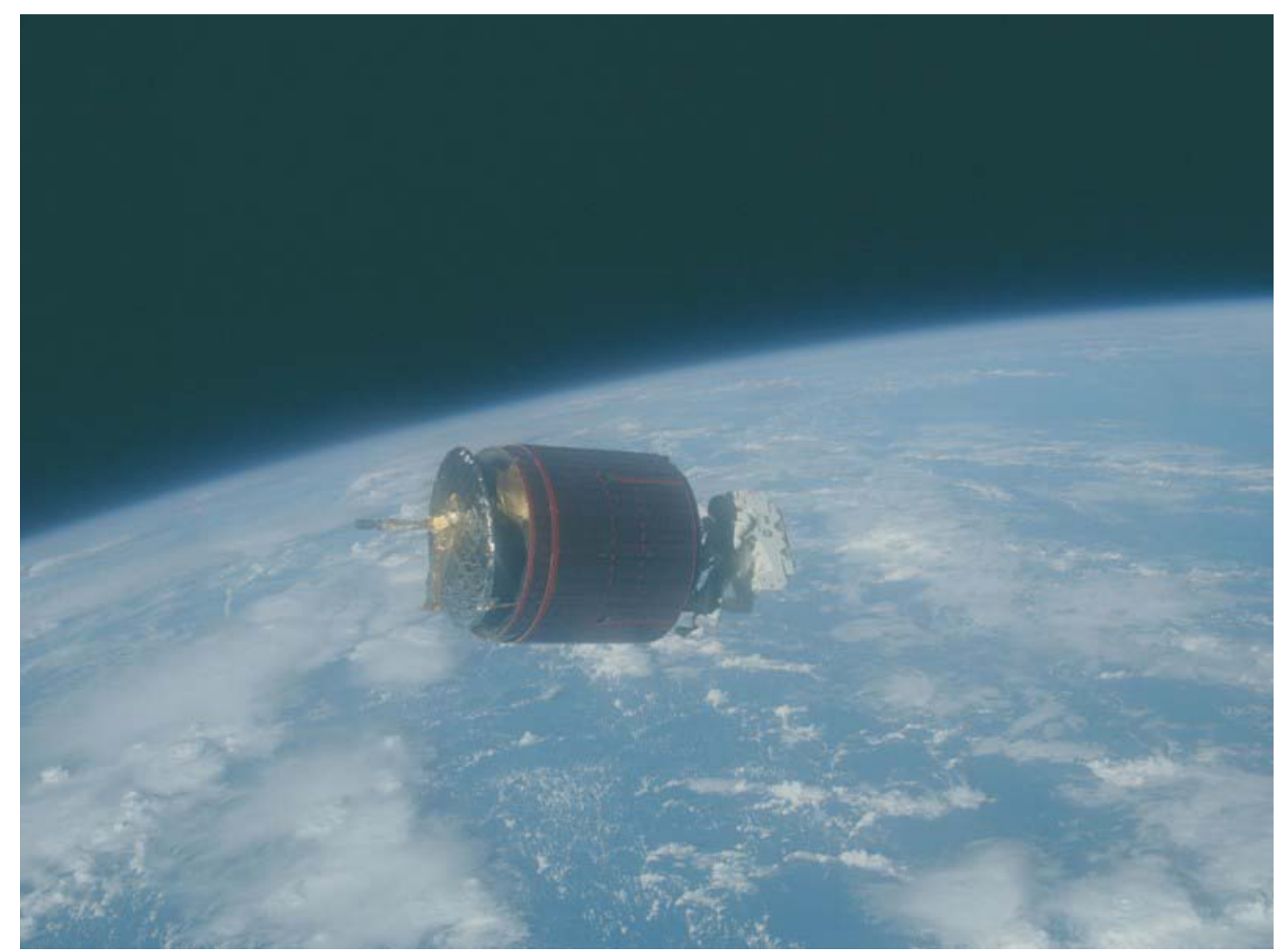

Figure 4 STS-51A MMU Capture of Palapa B-2 Satellite

In April 1985, Shuttle crewmembers on STS-51D deployed the LEASAT-3 satellite, however its perigee kick motor failed to ignite. The crew performed the first unscheduled EVA in NASA history when crewmembers attached lever extenders the sequencer start lever on the LEASAT satellite, which enabled the crew to activate the motor using the Remote Manipulator System (RMS). Although the crew was successful in actuating the lever, the kick motor still did not initiate. In August, the STS-51I EVA crew revisited LEASAT to berth, complete repairs and redeploy the satellite. 


\section{EVA - Don't Leave Earth Without It}

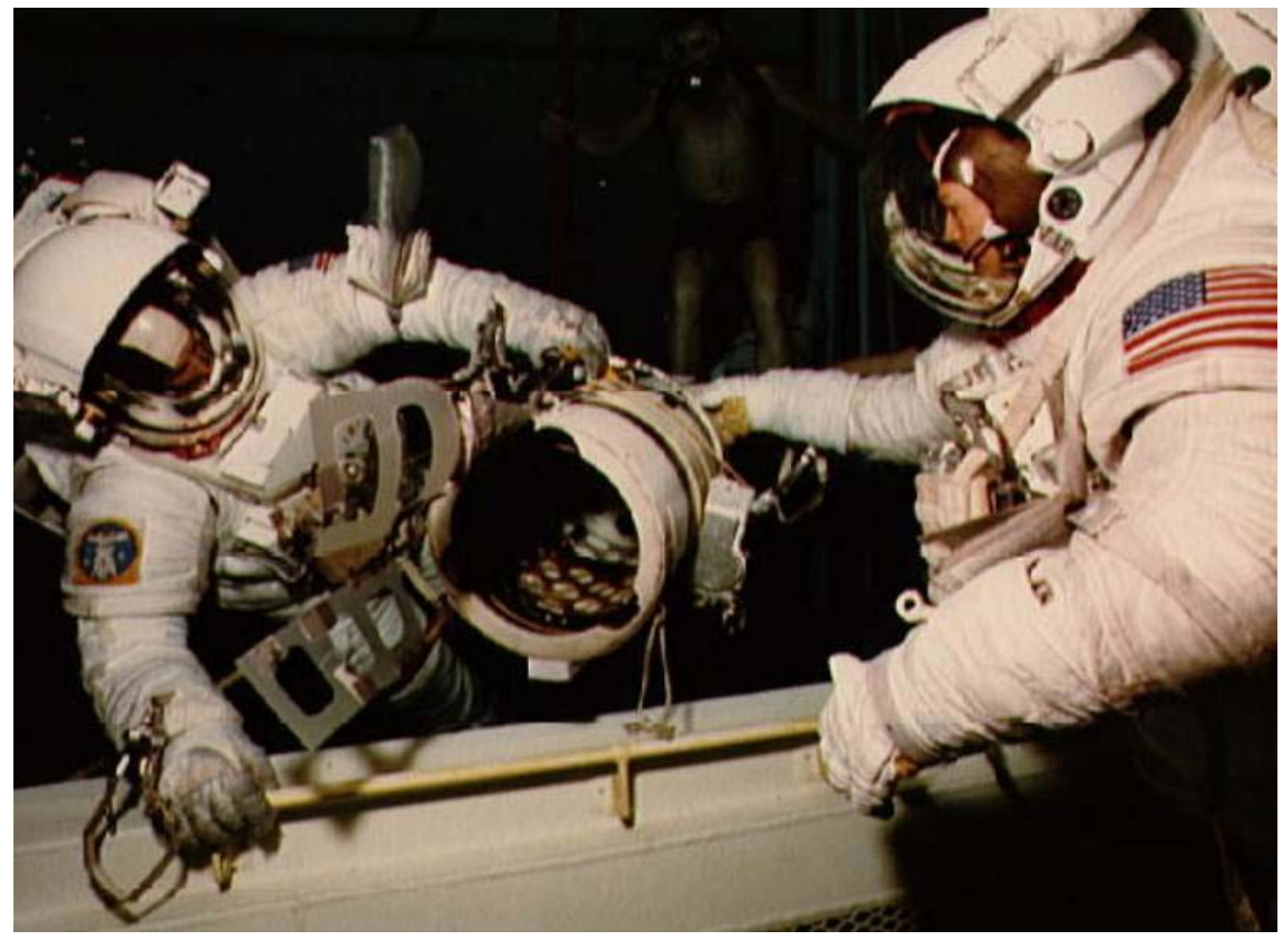

Figure 5STS-51D WETF Evaluation of Flyswatter installation on Shuttle Robotic Manipulator System (RMS)

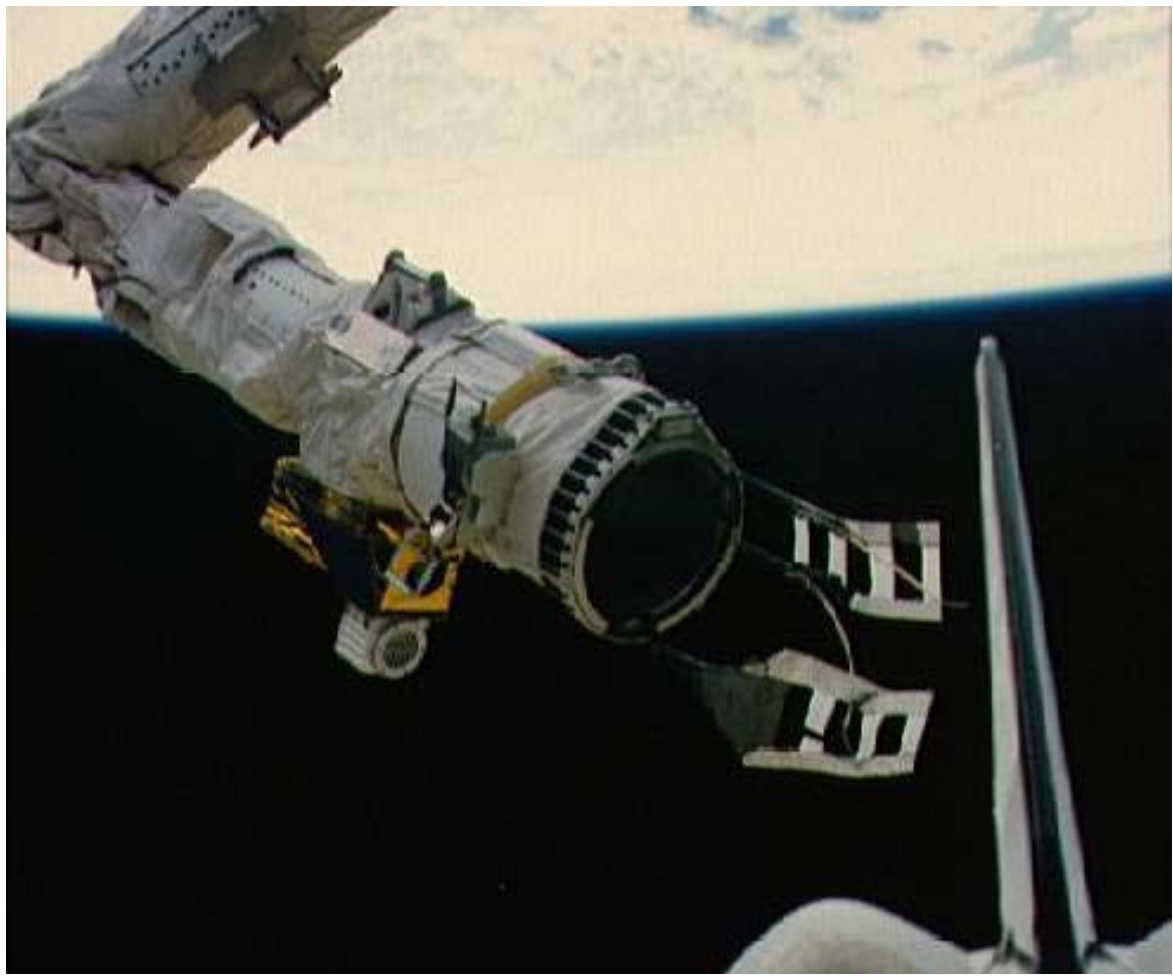

Figure 6 STS-51D Flyswatter affixed during EVA to RMS with help of Payload Retention Device (PRD) 


\section{EVA - Don't Leave Earth Without It}

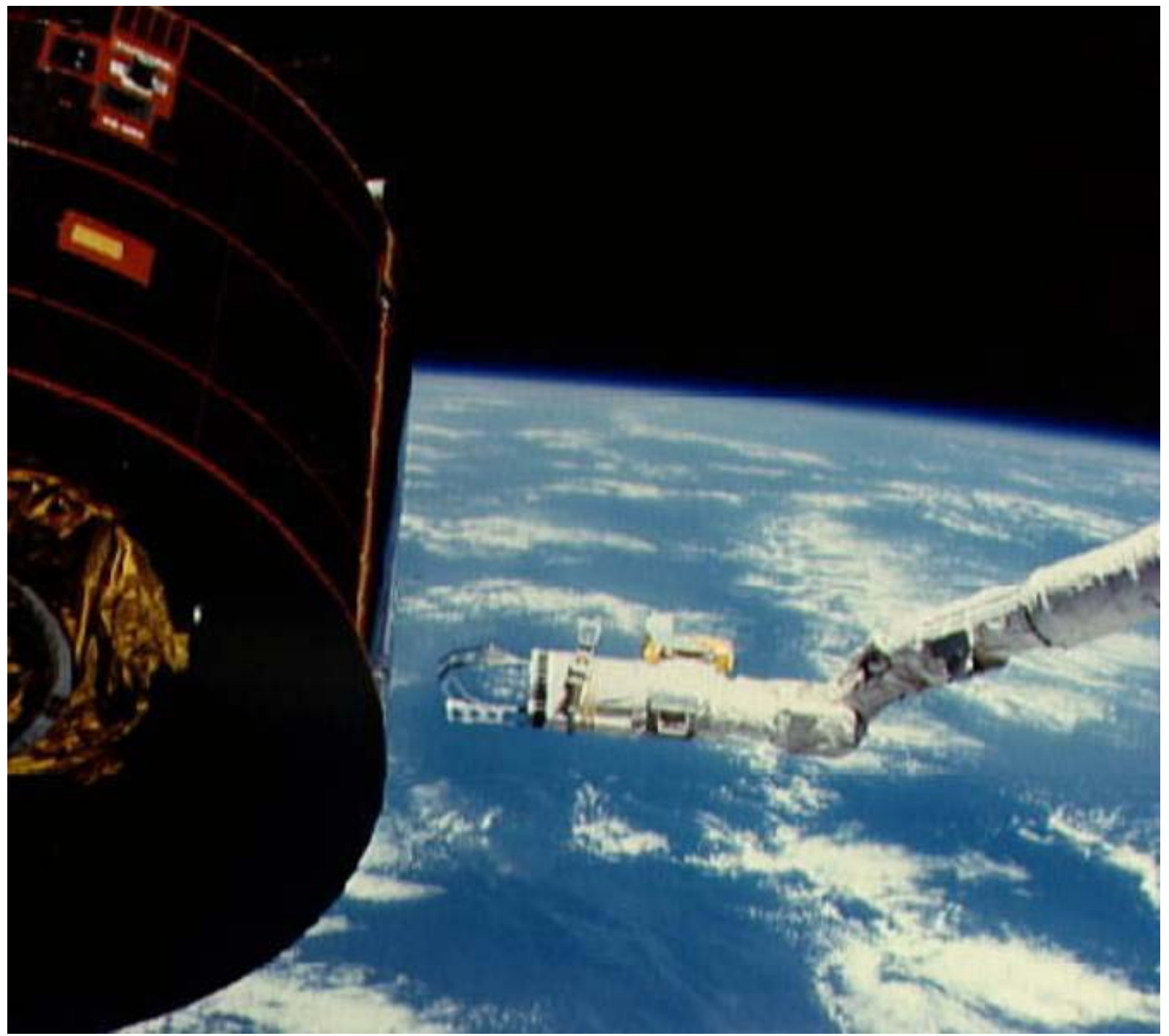

Figure 7STS-51D Flyswatter in position to engage Sequencer Start Lever on LEASAT-3

STS-37 in April 1991 saw another unscheduled EVA, when EVA crewmembers were sent into the payload bay to deploy an antenna that jammedon the Gamma Ray Observatory, just prior to the satellite being launched from the payload bay. STS-49, which flew in May 1992, included the first - and, to date, only - three-person EVA in history. STS-49 was also the first shuttle mission with four EVAs. During that mission, the EVA crew attempted to capture Intelsat VI using a specialized device. When all attempts at grappling the satellite using a specially designed capture bar failed, the Orbiter was flown up to Intelsat so that the three-person EVA crew could capture the satellite by hand and mate it to a perigee kick motor. A kick motor was installed on Intelsat, and the Shuttle crew deployed the satellite. EVA 3 set the record for longest EVA (8 hours 29 minutes), eclipsing the record set by the Apollo 17 EVA crew. 


\section{EVA - Don't Leave Earth Without It}

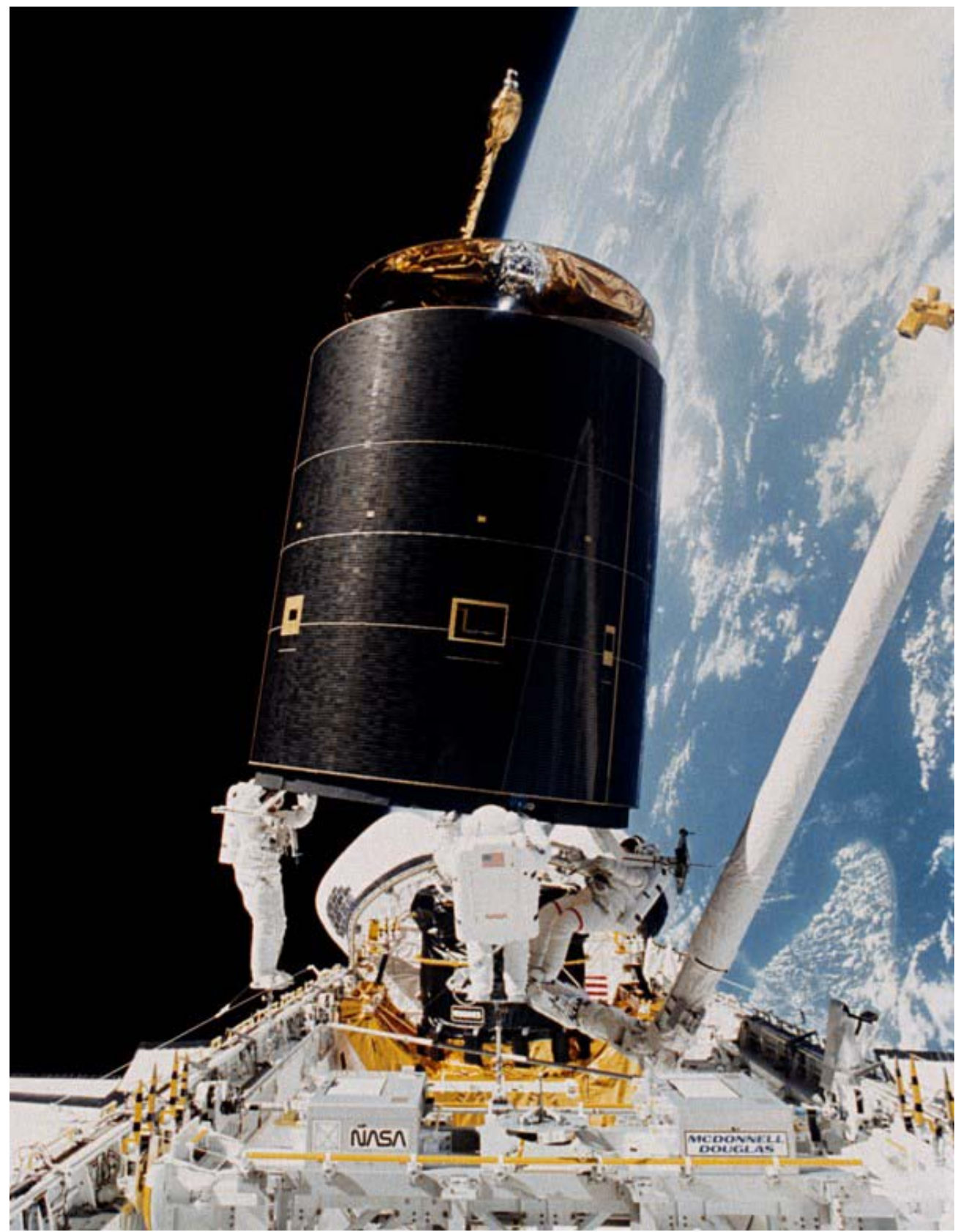

Figure 8 STS-49 Three-crewmember EVA grapple of Intelsat

Satellite rescue tasks involving EVA crewmembers physically handling large objects were not originally envisioned in the operational concept of the EMU, so engineers began to test and investigate the loads that a massive object like a satellite could impart into a Space Suit Assembly (SSA). SSA engineers discovered that it was possible, given the right set of circumstances, for a crewmember to hold on to a satellite in such a way that it could impart large enough loads to essentially pull an arm off the suit. 
Based on the results of the testing and on the increasing dependence of missions on EVA, the SSA was redesigned to improve its safety. The Hard Upper Torso (HUT) was redesigned to eliminate failure modes. In the arms, waist, legs, and boots, the axial restraints were upgraded to increase safety factors and reduce the effort required to work in the suit.

The experience gained from the satellite rescue missions and the crewmember's need for greater mobility and tactility drove the need for the EMU glove improvements, which led to two design iterations: the 3000-Series and 4000-Series EMU gloves. The 3000 -Series glove used lighter weight nylon fabric in its restraint, which improved the glove's flexibility, and changed the material of the palm from Kevlar to Nomex coated with a rubber-like material called RTV (which stands for Room Temperature Vulcanizing). The 3000-Series glove, introduced in 1984, proved to be a more robust glove than the original 1000 -Series, and it was able to enjoy an extended service life.

The 4000-Series glove was phased into service beginning in 1986 and addressed shortcomings in the 3000 -Series design by eliminating excess bladder material and changing the restraint design to eliminate pressure points at the thumb crotch.

These early EVAs helped NASA gain valuable experience working with large space structures. The EVAs also allowed NASA to refine the design of the EMU and tools based on real world use, rather than in a laboratory or training environment. The lessons learned from these EVAs were vital for the missions that lay ahead. 


\section{EVA - Don't Leave Earth Without It}

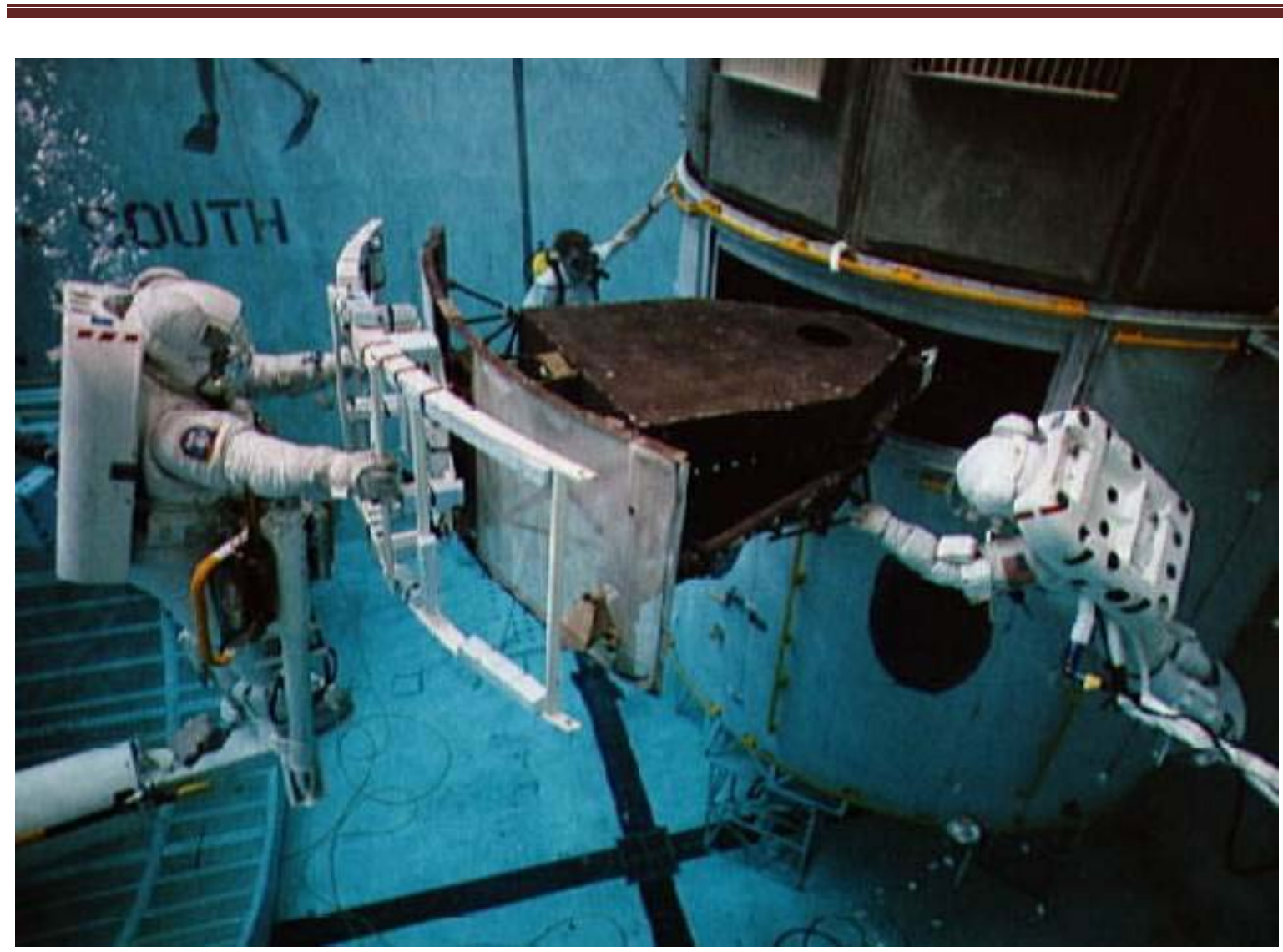

Figure 9 STS-61 WETF training for Wide-Field Planetary Camera (WFPC)removal/installation

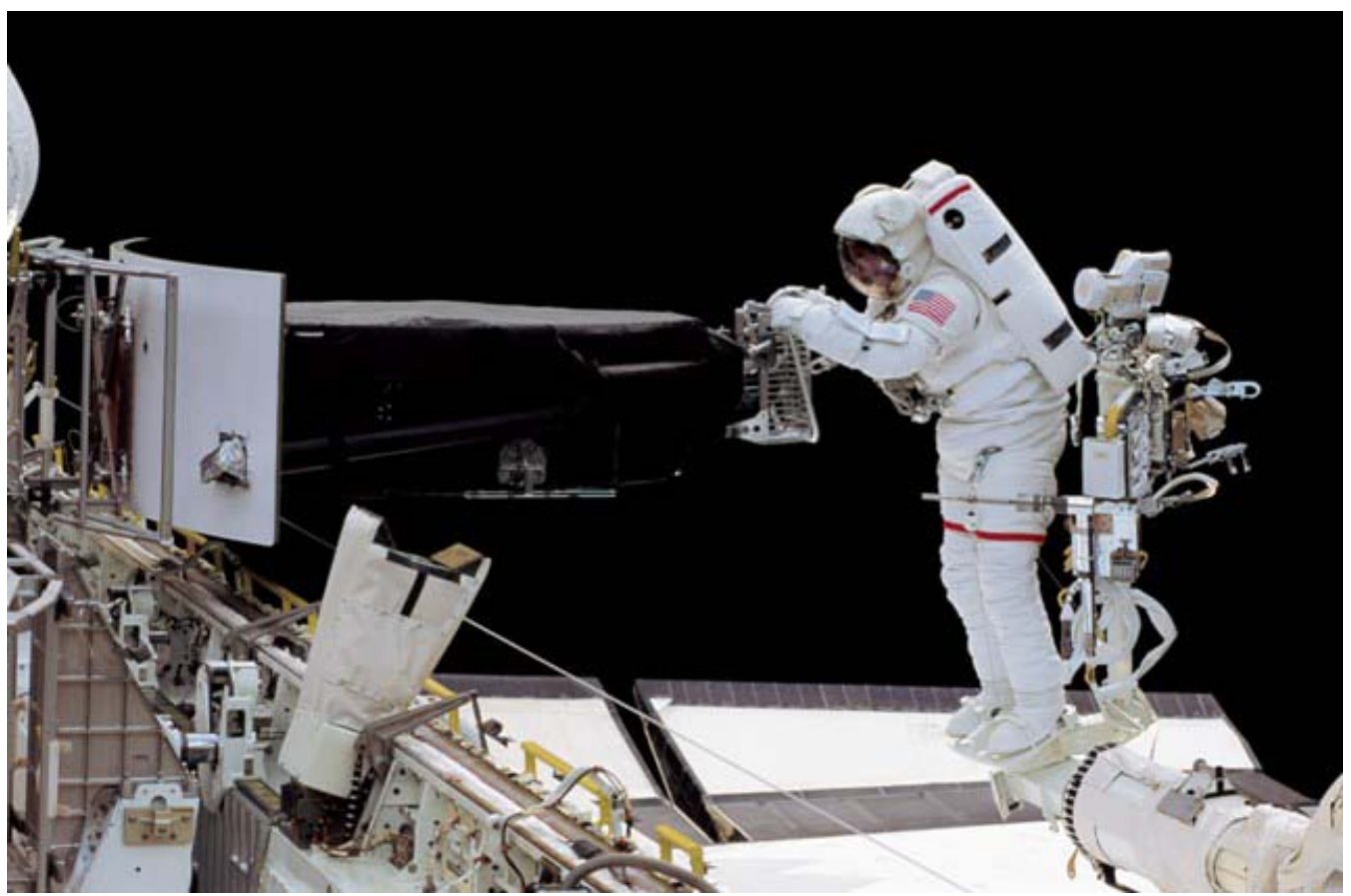

Figure 10 STS-61 On-orbit removal and temporary stowage of WFPC 


\section{EVA - Don't Leave Earth Without It}

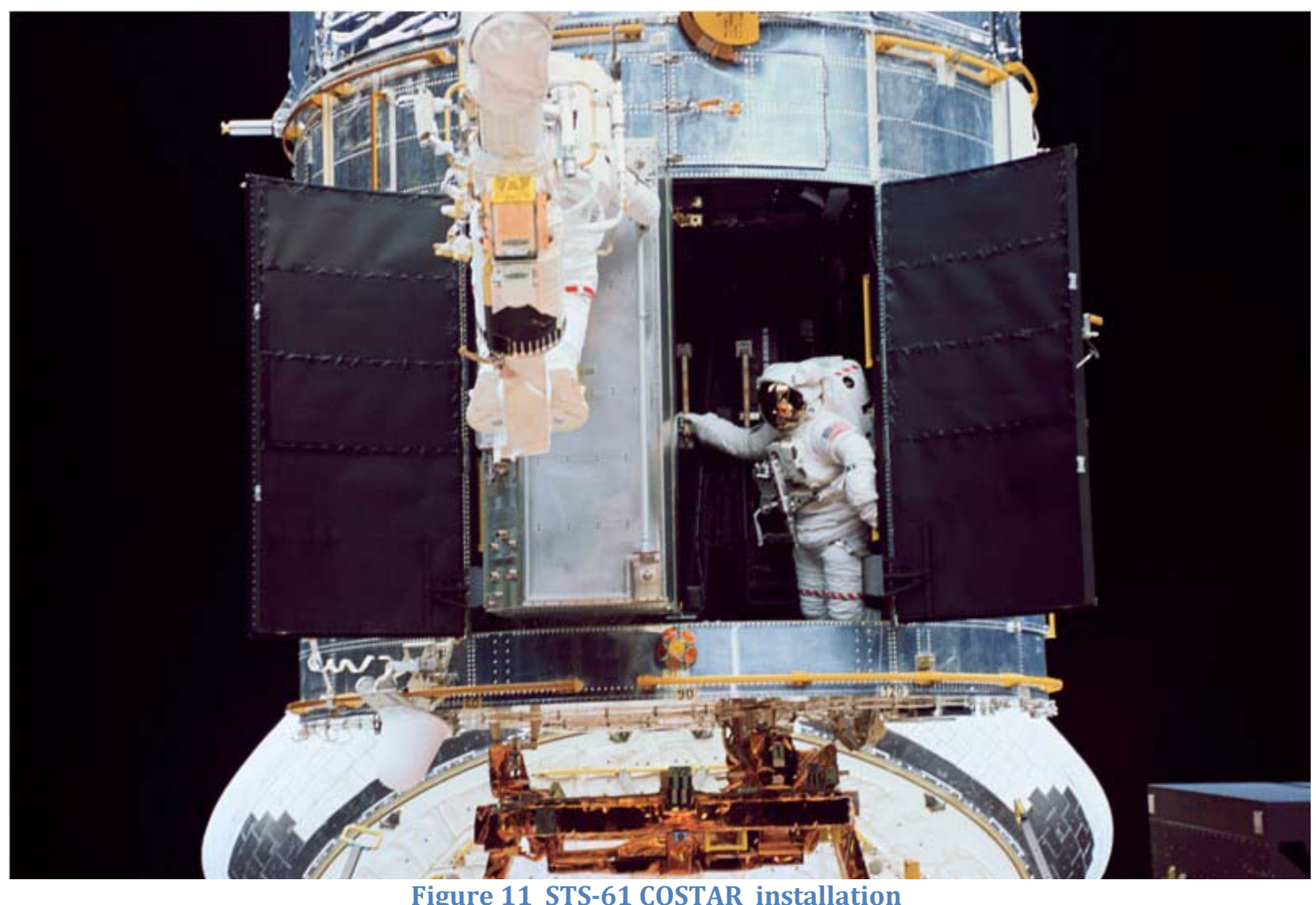

Four years later, in February 1997, STS-82 visited HST on SM 2 and swapped two spectrograph instruments for an infrared spectrometer, called the Near Infrared Camera and Multi-Object Spectrometer (NICMOS), and a new spectrograph, called the Space Telescope Imaging Spectrograph (STIS). Both of these instruments included a correction factor for the flawed mirror optics. The EVA crew also replaced thermal insulation on the exterior of the telescope. The spectrometer added an infrared camera to HST, which expanded the telescopes capability to include the infrared light spectrum. 


\section{EVA - Don't Leave Earth Without It}

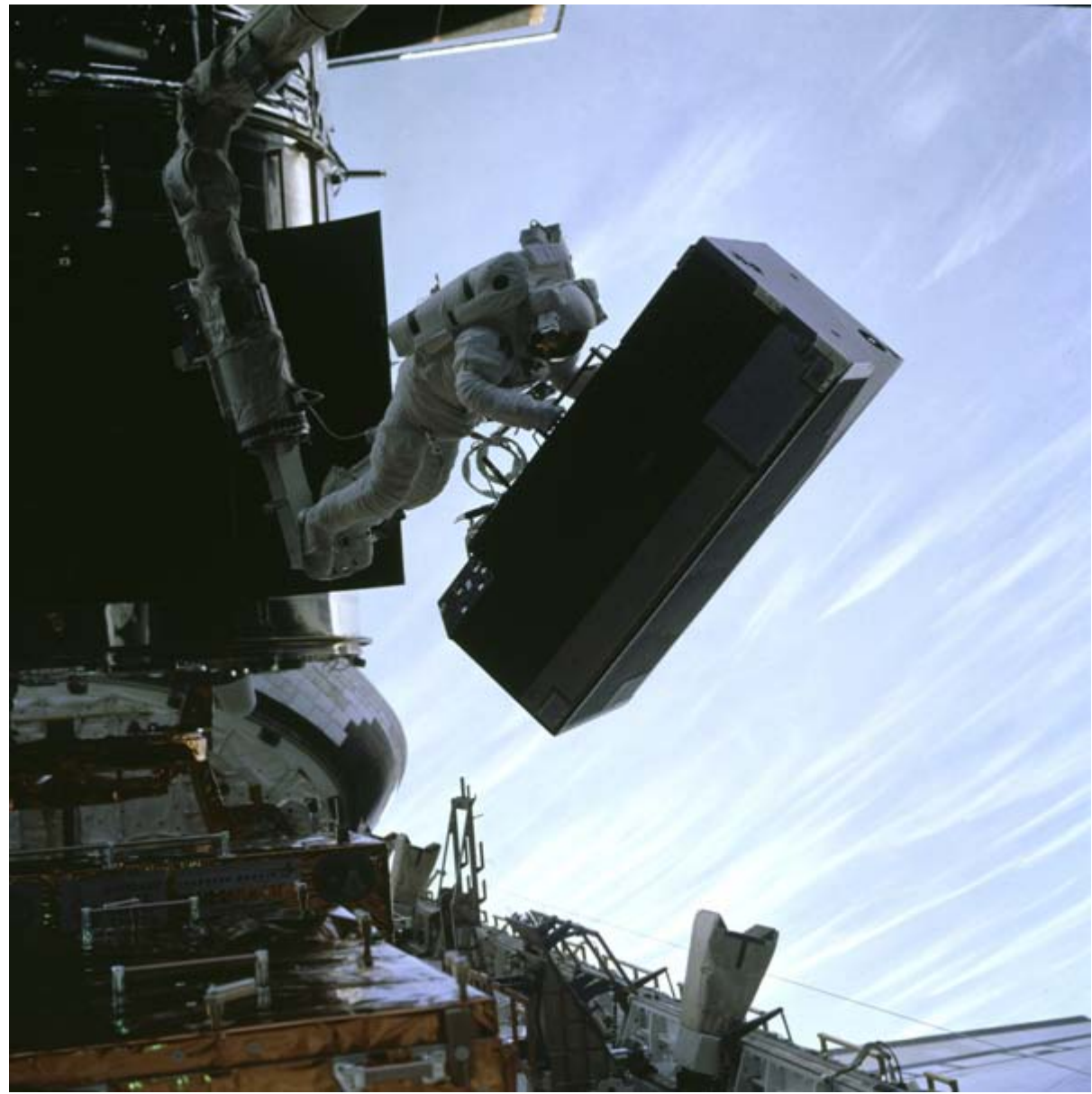

Figure 12 STS-82 NICMOS preparation for installation

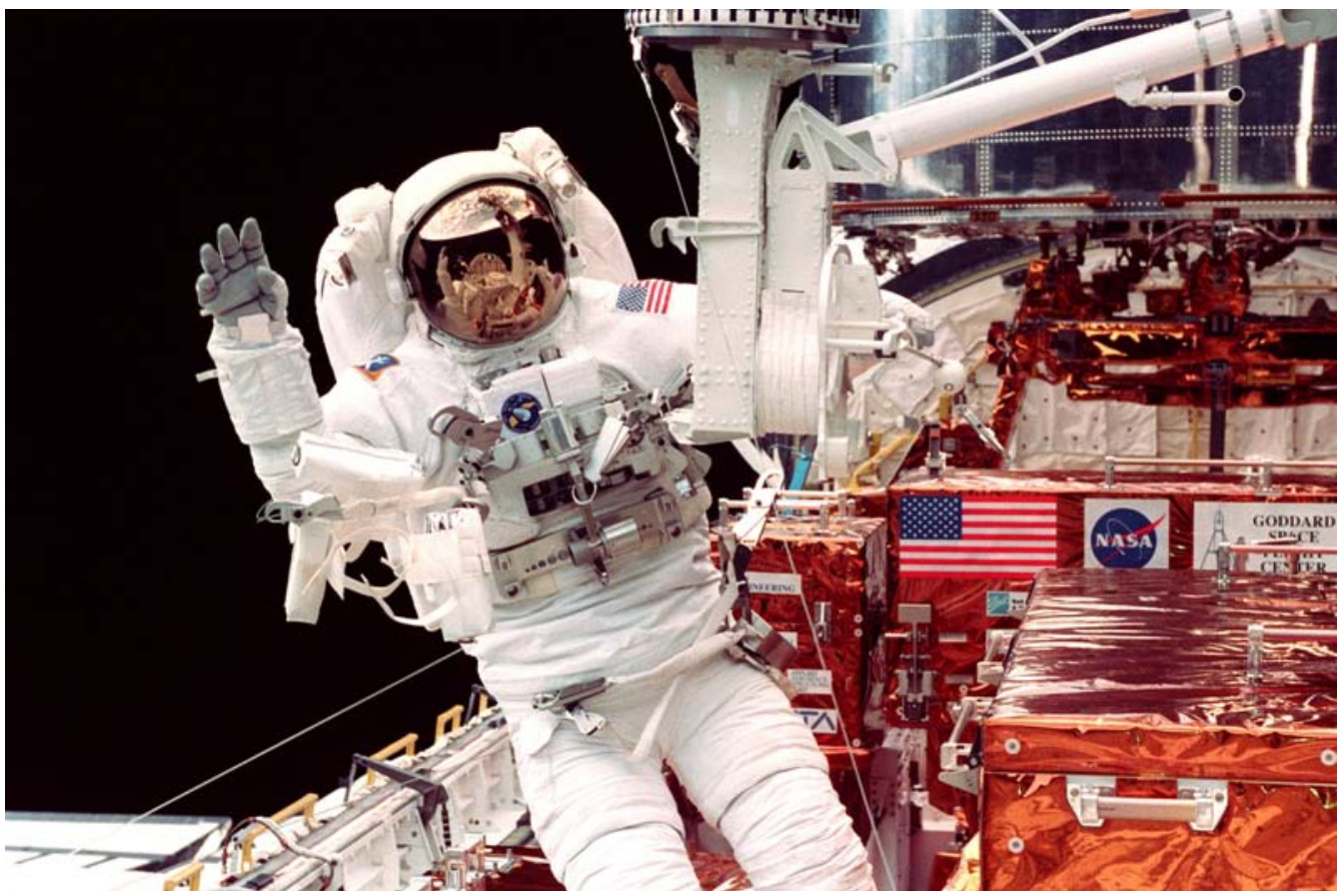

Figure 13 STS-82 Manipulator Foot Restraint (MFR) and tool preparation for EVA 
In December 1999, the third servicing mission, STS-103 or SM 3A, visited HST, and brought with it significant upgrades to the telescope. All six gyroscopes on HST were replaced after four gradually began to fail prior to the mission. An upgraded computer, which was twenty times faster and had six times more memory than the original computer, was installed during EVA 2. The crew installed a kit that protected the batteries from overcharging and overheating, replaced a failed S-band transmitter that allowed HST to send data to the ground via NASA's Tracking and Data Relay Satellite System, and installed a spare solid state data recorder, which replaced a reel-to-reel recorder and increased the storage capacity from 1.2 gigabytes to 12 gigabytes. The EVA crew also upgraded a Fine Guidance Sensor, lubricated hinges on the doors and repaired external thermal insulation that had degraded.

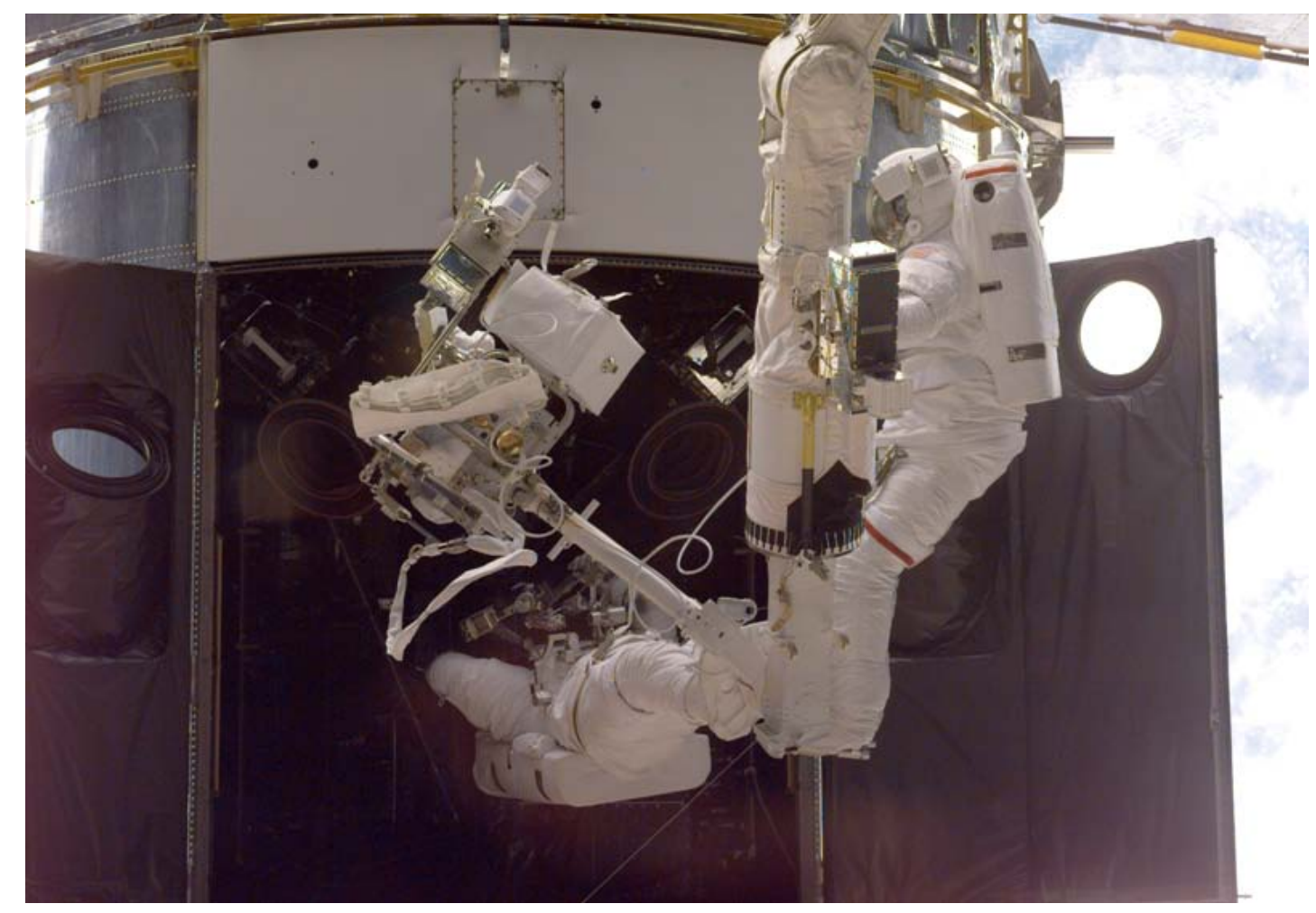

Figure 14 STS-103EVA Crew on Shuttle Robotic arm positioned inside HST 


\section{EVA - Don't Leave Earth Without It}

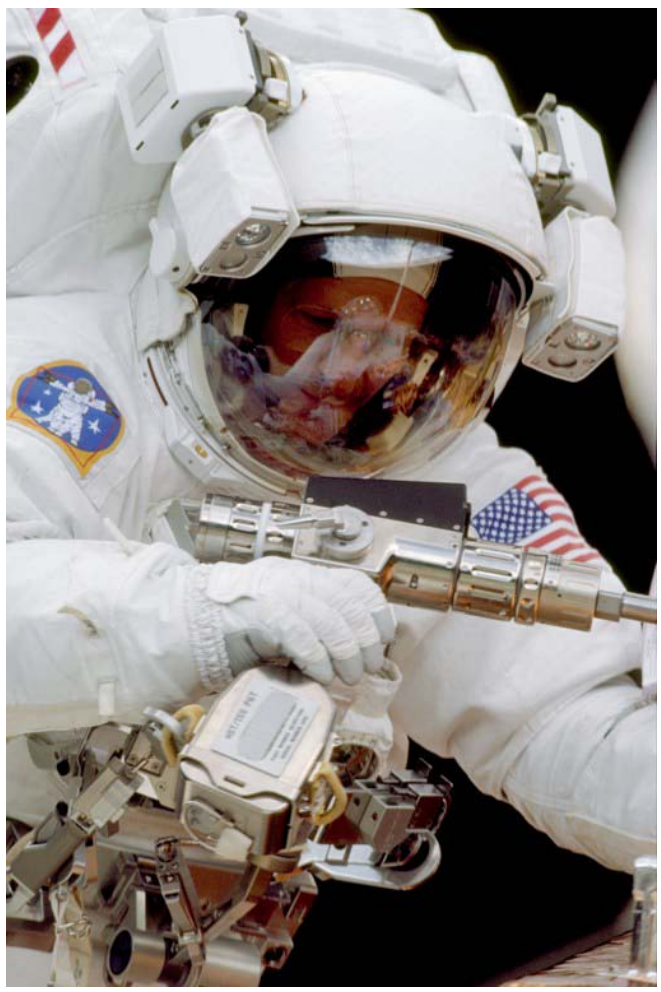

Figure 15 STS-103 Use of Pistol Grip Tool (PGT) to secure bolted fastener on HST Flight Support Equipment

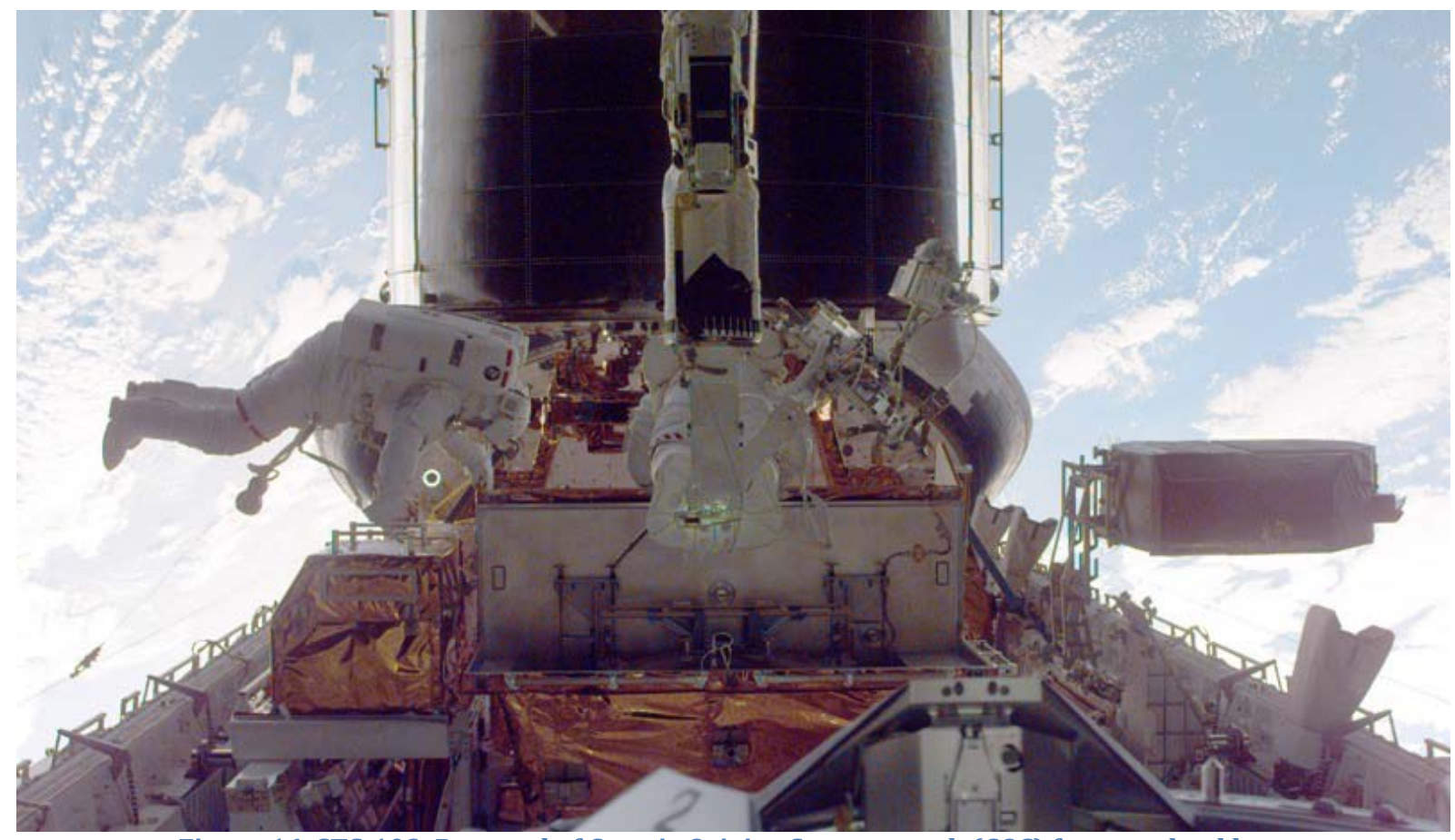

Figure 16 STS-103 Removal of Cosmic Origins Spectrograph (COS) from payload bay

STS-109 or SM 3B followed in March 2002, and during the course of five EVAs over five consecutive days, the crew installed new, more powerful solar arrays; a new 
Power Control Unit that is compatible with the solar arrays; a new instrument, called the Advanced Camera for Surveys (ACS) after removing the Faint Object Camera; and a Cryocooler for NICMOS. With the installation of ACS, COSTAR was no longer needed, as each of the upgraded instruments on board HST corrected for the aberration in the mirror.

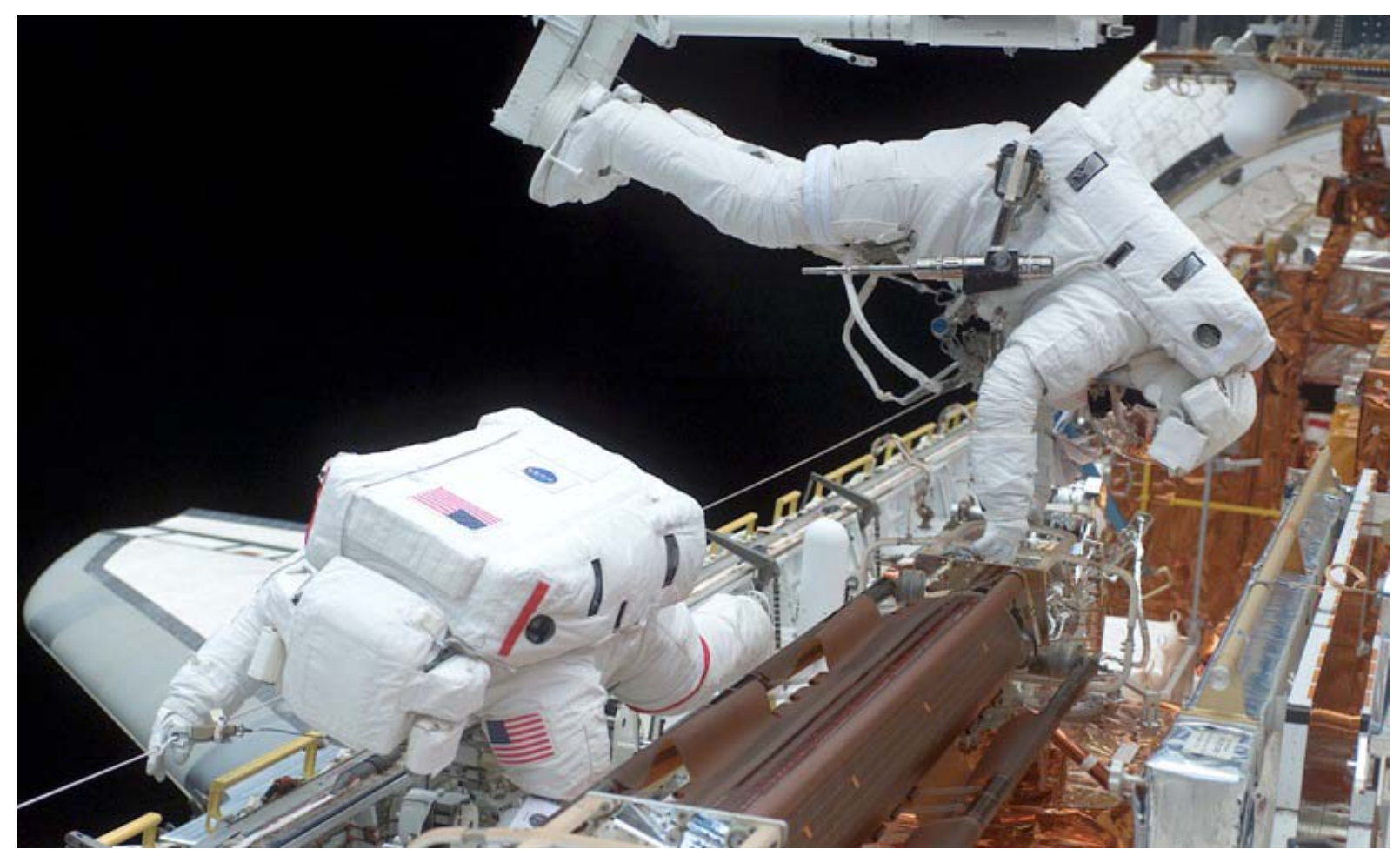

Figure 17 STS-109 Solar Array preparation for FSE removal and HST installation 


\section{EVA - Don't Leave Earth Without It}

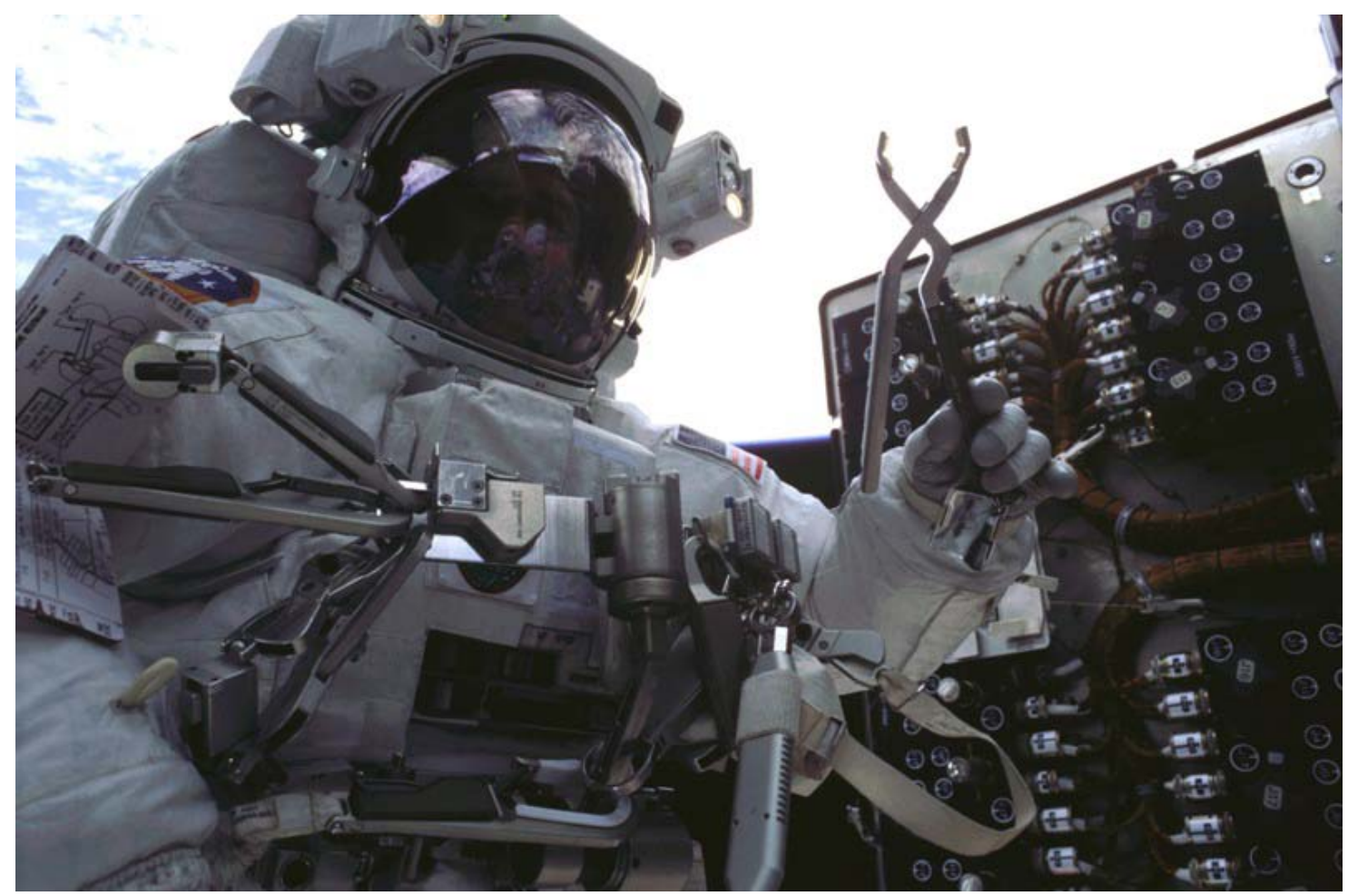

Figure 18 STS-109 HST Connector Tool is ready to assist with connector removal/installation

SM4, the fifth servicing mission was conducted on STS-125 in May 2009. This was the Shuttle's final visit to HST, and five EVAs were performed to remove COSTAR and install two new instruments: the Cosmic Origins Spectrograph and the Wide Field Camera 3. The crew also repaired two failed instruments, the ACS and the STIS, and upgraded the thermal insulation on the exterior of the spacecraft. A soft-dock mechanism was also installed on HST that will allow an unmanned spacecraft to safely de-orbit it at the end of its life.

In each one of these missions, the EVA crewmembers repaired, replaced or upgraded systems on the spacecraft to improve its condition. More importantly, they improvised workarounds and adaptively solved problems real time during the spacewalks. This real-time adaptability is often overlooked when trading EVA capability against robotic capability. The repair EVAs of HST also helped prove that astronauts were capable of performing complicated assembly and maintenance tasks during EVAs - helping to pave the way for the construction of the International Space Station (ISS). 


\section{EVA - Don't Leave Earth Without It}

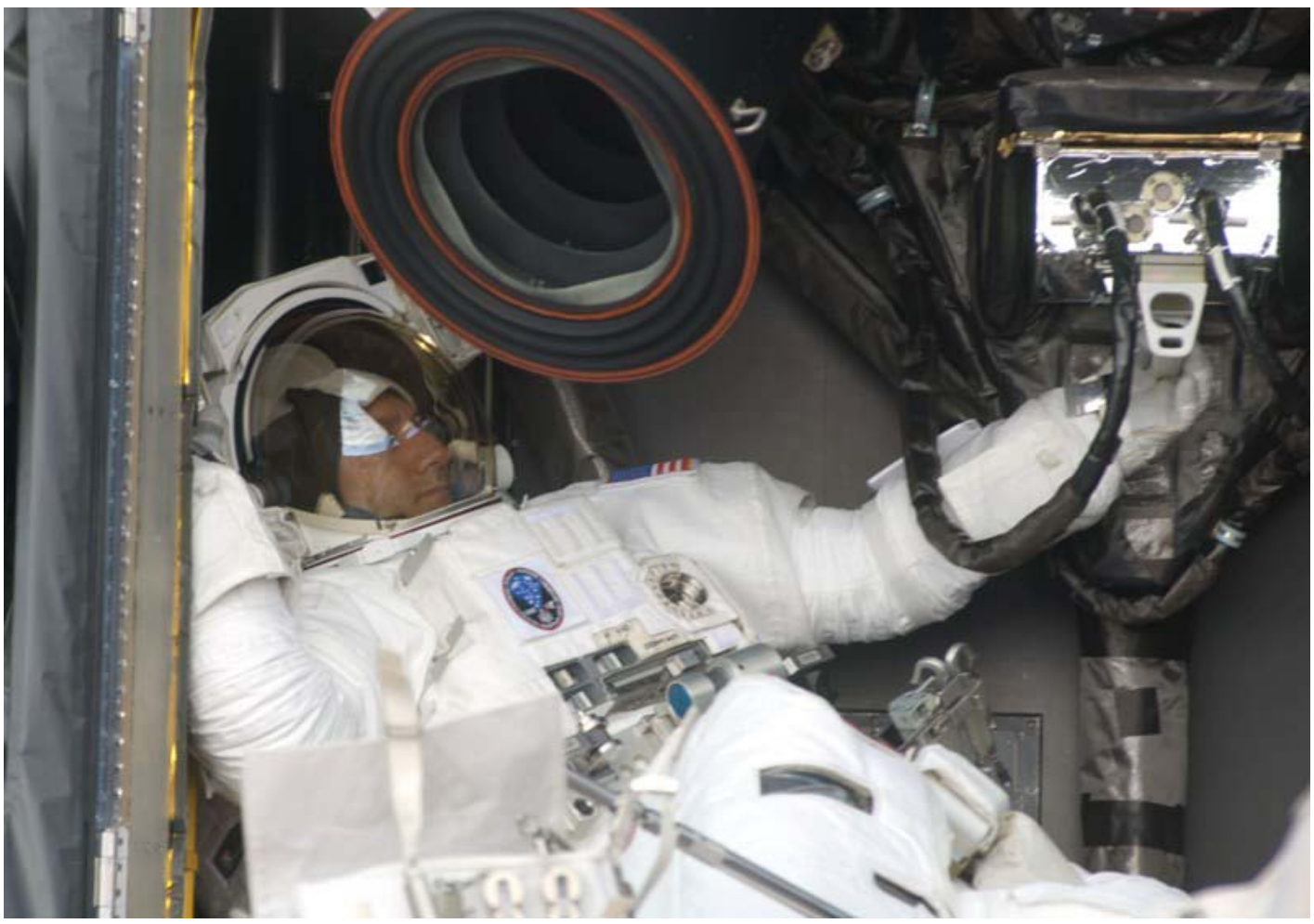

Figure 19STS-125 Massimino inside HST to remove/replace the Reaction Wheel Assembly (confirm right pic)

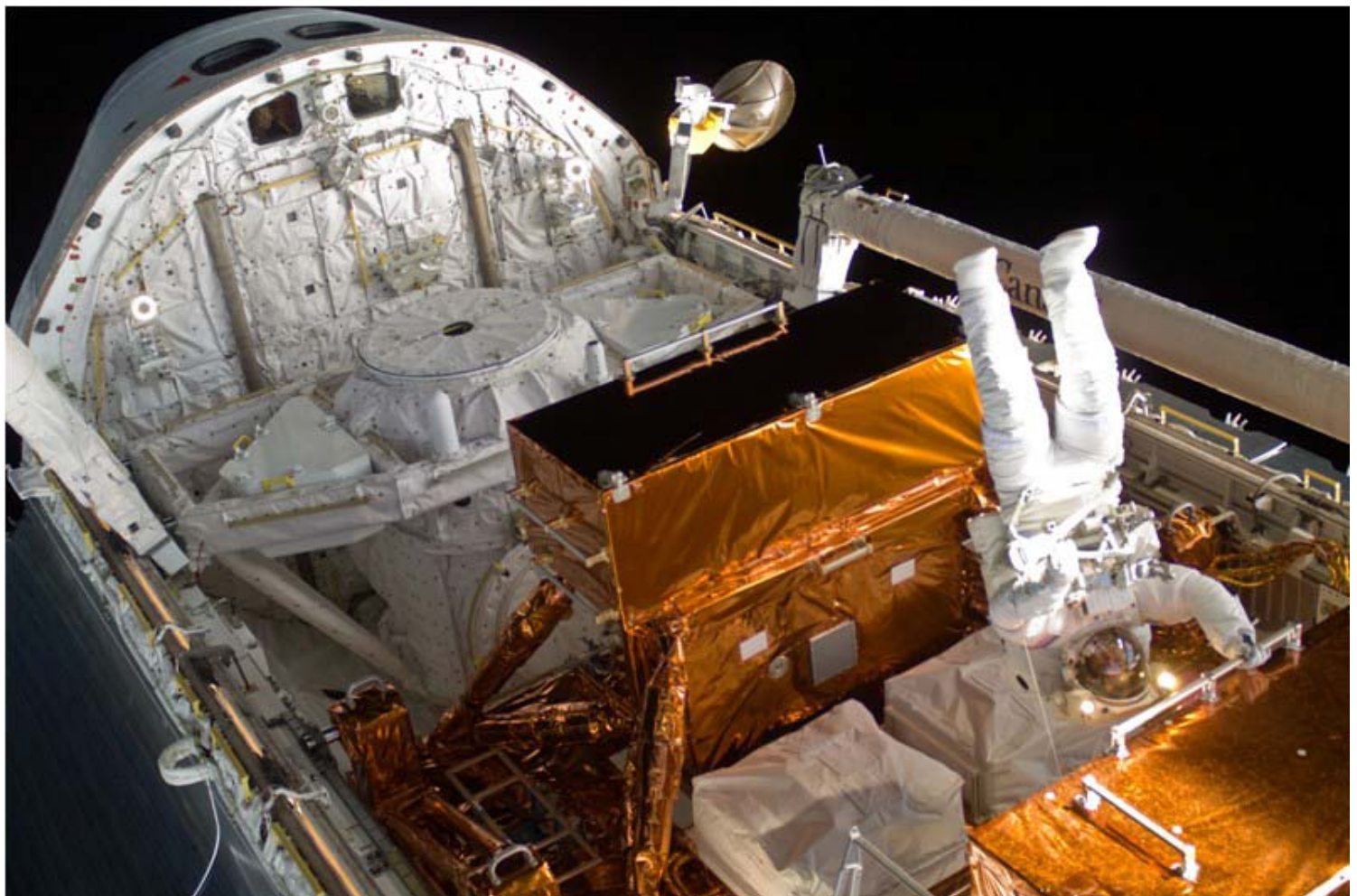

Figure 20 STS-125 View from crewmember on Shuttle RMS MFR looking back into payload bay 


\section{EVA - Don't Leave Earth Without It}

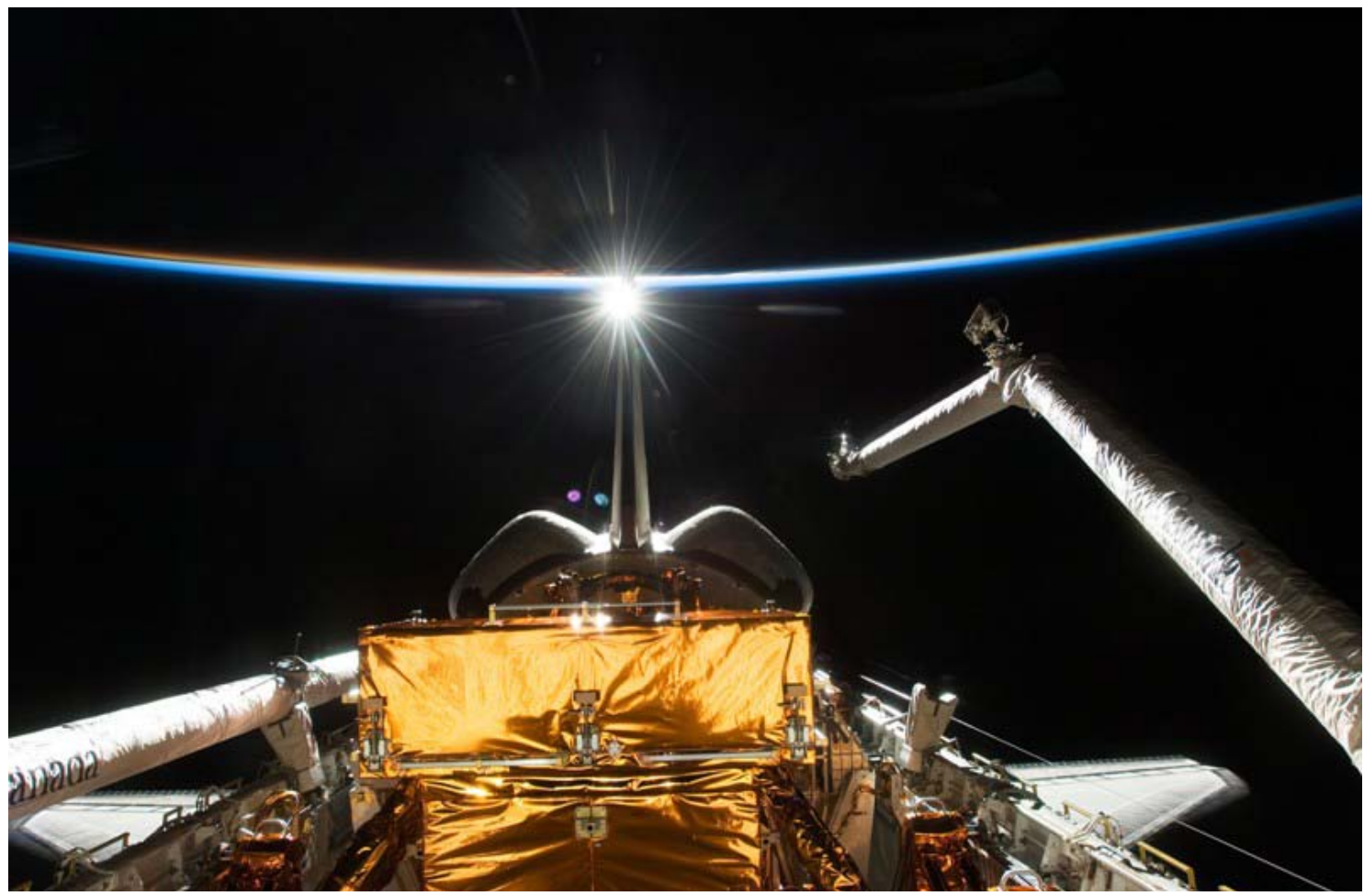

Figure 21 STS-125 Servicing complete after re-deployment of HST

\section{ISS Construction}

In the early 1990's, as the plan for the International Space Station was coalescing, it became clear that the construction of ISS was going to require a large number of EVAs to complete. This EVA-intensive period was known as the Wall of EVAs. Between 1998 and 2011, ninety-eight EVAs were conducted out of the Shuttle and ISS airlocks to assemble ISS while the Orbiter was docked. During the nearly 650 hours of spacewalks, astronauts assembled, unfurled, bolted, connected and attached hundreds of components to complete ISS. Twenty-five of the first twenty-six EVAs were conducted out of the Shuttle airlock. After the installation of the Quest joint airlock on STS-104/7A, astronauts began executing EVAs from ISS. Because EMUs are limited on the number of EVAs they can perform before they need to be maintained on the ground, astronauts used Shuttle-based EMUs for ISS EVAs. In taking this logistical approach to EVA, the Shuttle crews were able to provide both primary and backup EMUs for the EVA crews in order to protect for any possible hardware problem with the suits. 


\section{EVA - Don't Leave Earth Without It}

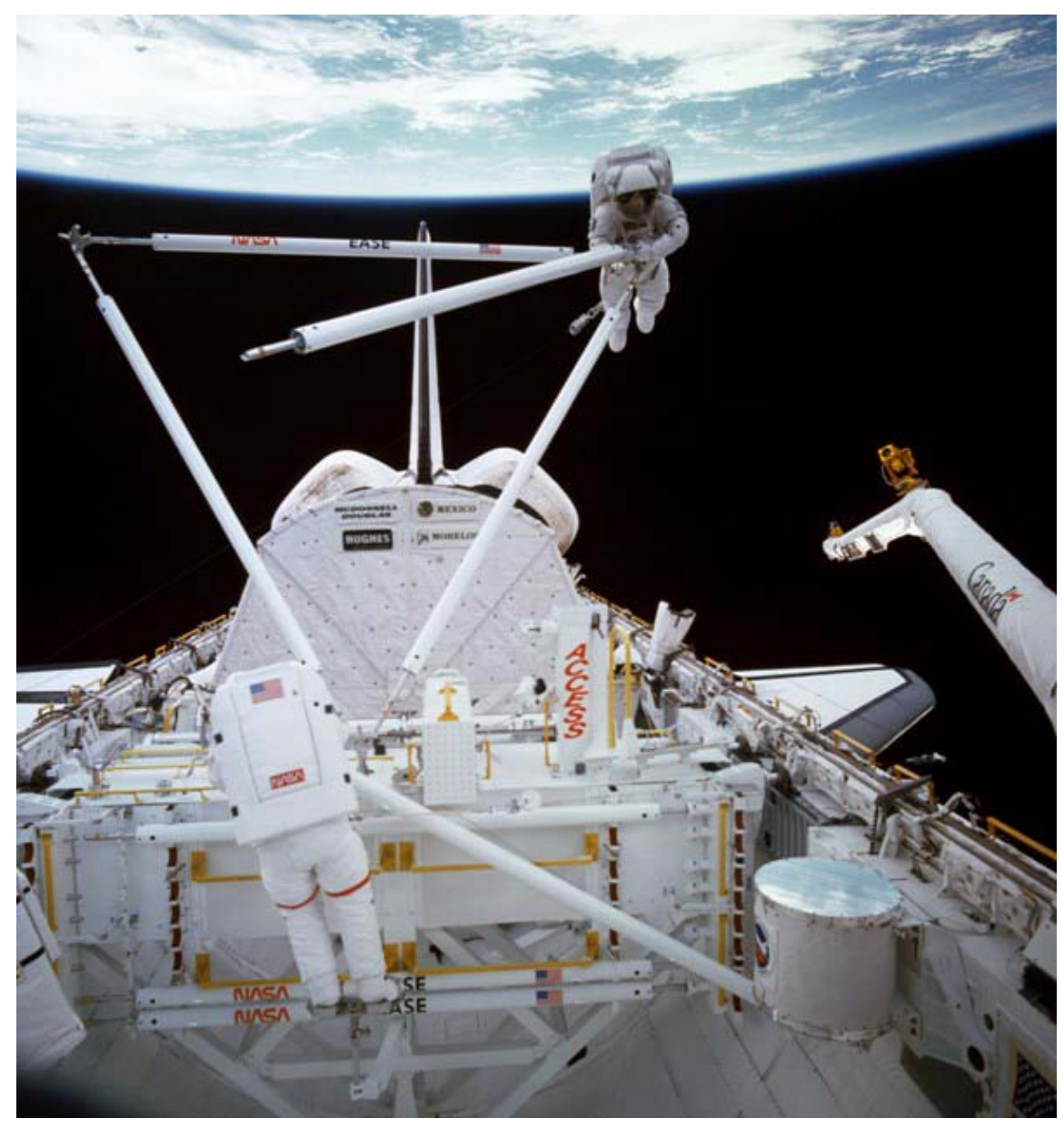

Figure 22 STS-61B ACCESS/EASE demonstration of EVA Construction Capabilities and Techniques 


\section{EVA - Don't Leave Earth Without It}

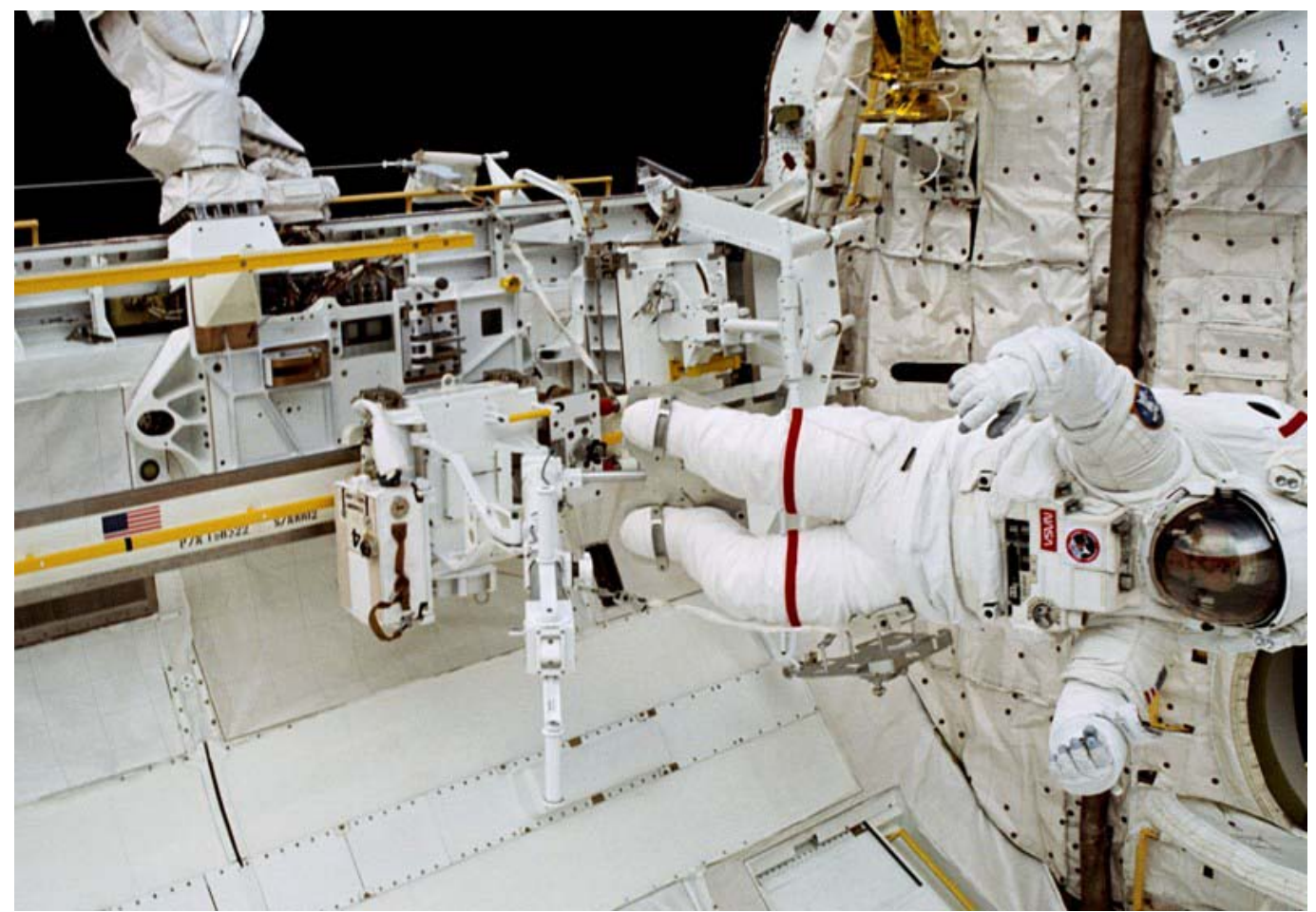

Figure 23 STS-37 Evaluation of Crew and Equipment Translation Aids (CETA)

In preparation for the unprecedented number of EVAs that were required for the construction of ISS, the EMU underwent a major upgrade program, called EMU Enhancements. The major goals of the program were to provide on-orbit logistical options to minimize the amount of EMU hardware launched to protect for missions conducting multiple EVAs with more than two EVA teams.

From an on-orbit standpoint, one of the most time-intensive tasks that astronauts were asked to perform was space suit resizing. Resizing the baseline Shuttle EMU consisted of unlacing a fabric strip and lacing in a new one. The process of resizing an EMU usually took about three hours for a pair of arms and involved a needle (never a good thing around a space suit) and sizing cord.

Engineers, realizing time on orbit is precious and that it would not be possible to send an entire complement of EMU sizes to orbit, began to look for ways to improve the suit and decrease the time required to resize the EMU. The EMU engineers innovated a set of interchangeable arm and leg components that can be threaded on to the rest of the suit without the use of any tools. If the suit's arm length wasn't appropriate for a crewmember, changing the size was as simple as unscrewing one arm and screwing on a different one. The change-out process for a pair of arms was reduced from about three hours to about fifteen minutes. Additionally, special features were added to the sizing system to minimize the number of softgood elements on-orbit. Metal sizing rings afforded crews the ability to make gross length changes of one inch across the arm span and up to two-and-a-half inches in the 
lower torso. Additionally, the new design allows for fine length adjustment in $1 / 4$ " increments across the arm span and $1 / 2$ " increments in the legs. Later upgrades also added an on-orbit adjustable waist design to the EMU.

Other changes to the SSA changed the interface between the HUT and the Primary Life Support System (PLSS) to allow crewmembers to remove and replace the Display and Controls Module (DCM) on the front of the EMU and the PLSS on the back. The design of the On Orbit Replaceable Unit (ORU) HUT also permitted onorbit replacement of arms in the EMU.

The PLSS was similarly redesigned in preparation for Shuttle missions to support ISS. The baseline PLSS design could only be integrated to the HUT during ground processing. The crew could not change components within the PLSS, other than the Battery and the Contamination Control Cartridge. The new design enabled both the PLSS and the Secondary Oxygen Pack to be removed and replaced on orbit. Although these features were originally intended to reduce on-orbit crew EVA preparation time, the ORU HUT, PLSS and DCM innovations also led to a tremendous reduction of time required to process theEMUs for flight and training events.

When originally certified in 1980, the EMU was certified for a maintenance life of seven EVAs, to be performed over a two-week period. It was clear that once ISS began flying, it would not be possible or practical to rotate EMUs on a bi-weekly basis, so the on-orbit life needed to be extended. Using a rigorous series of unmanned and manned vacuum tests, engineers demonstrated and certified that the EMU was capable of performing up to 25 EVAs over a period of six months to support ISS EVAs.

During Orbiter EVAs, crewmembers were "tied" to the Orbiter via a safety tether cable comprised of 3/32" braided steel. For non-ISS missions, if a crewmember became separated from the Orbiter, it was possible for the Orbiter pilot to physically maneuver the Orbiter to the crewmember. Orbiter rescue was not available with the Orbiter docked to ISS, nor was it available when the Orbiter was not in orbit. It is simply not possible to undock the Orbiter (from ISS) or maneuver the ISS (to the crewmember) in an adequate amount of time to retrieve a separated crewmember before the EMU runs out of consumables.

Engineers devised a contingency rescue propulsion system, called the Simplified Aid For EVA Rescue (SAFER), to address this problem. The SAFER integrates to the EMU Life Support System and provides a means for the crewmember to self-rescue should they become untethered from ISS.

The SAFER utilizes technology and capabilities from the MMU, but packaged in a smaller size so that it doesn't interfere with normal EVA hand translations, worksite operations, or airlock egress and ingress. The crewmember 'flies' the SAFER using a hand controller, which provides stabilization feedback. The SAFER uses compressed 
nitrogen gas as a propellant and employs gyroscopic sensors to determine crewmember's attitude.

The Space Shuttle and EVA were integral components in the construction of ISS. The Shuttle brought the largest elements to Low Earth Orbit and a combination of robotics and EVA successfully mated these elements and their associated fluid lines and power and data cables. The Shuttle Program and EVA successfully demonstrated that large, complex space structures could be built in space.

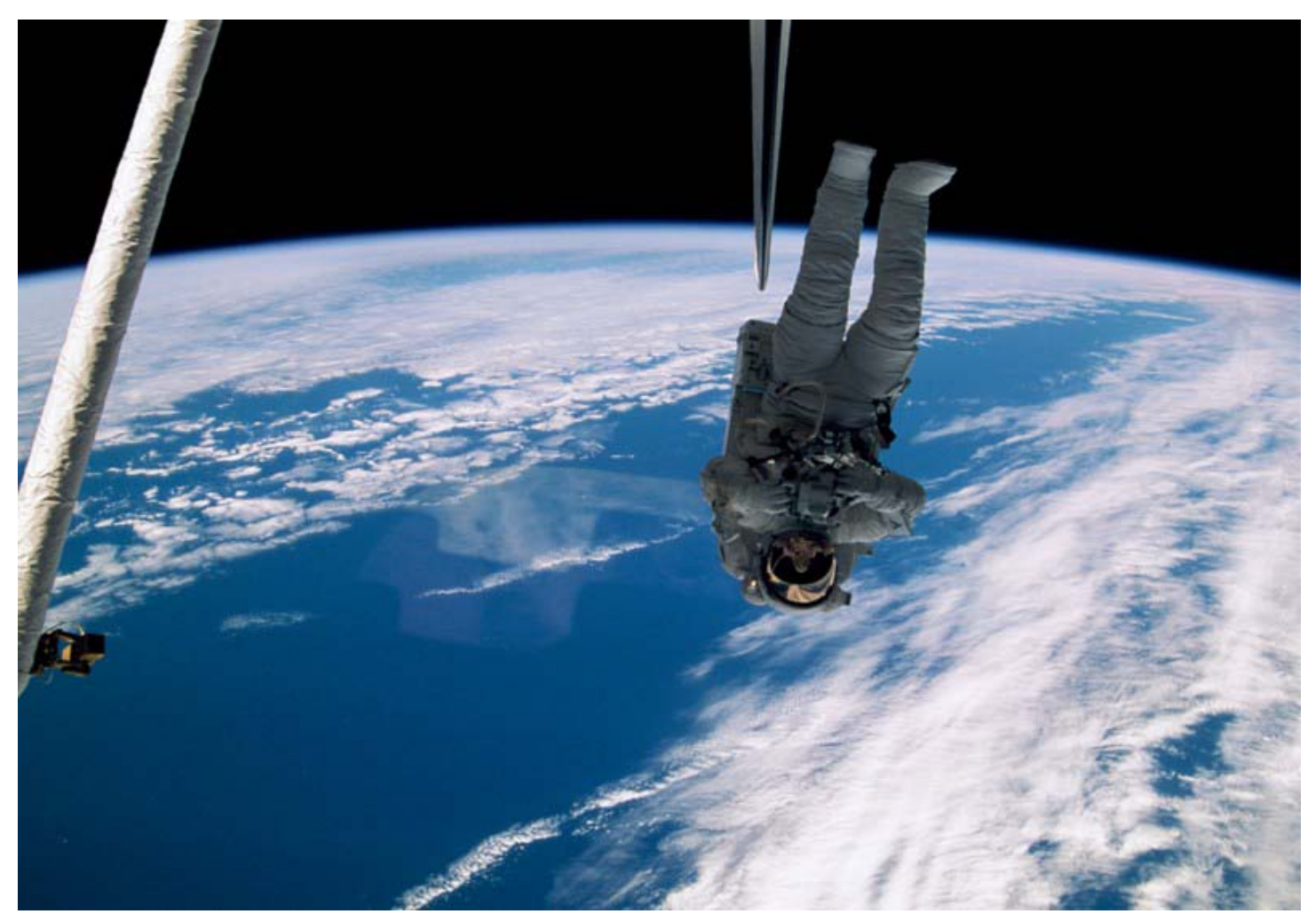

Figure 24STS-64L Detailed Test Objective (DT0) evaluating EVA SAFER 


\section{EVA - Don't Leave Earth Without It}

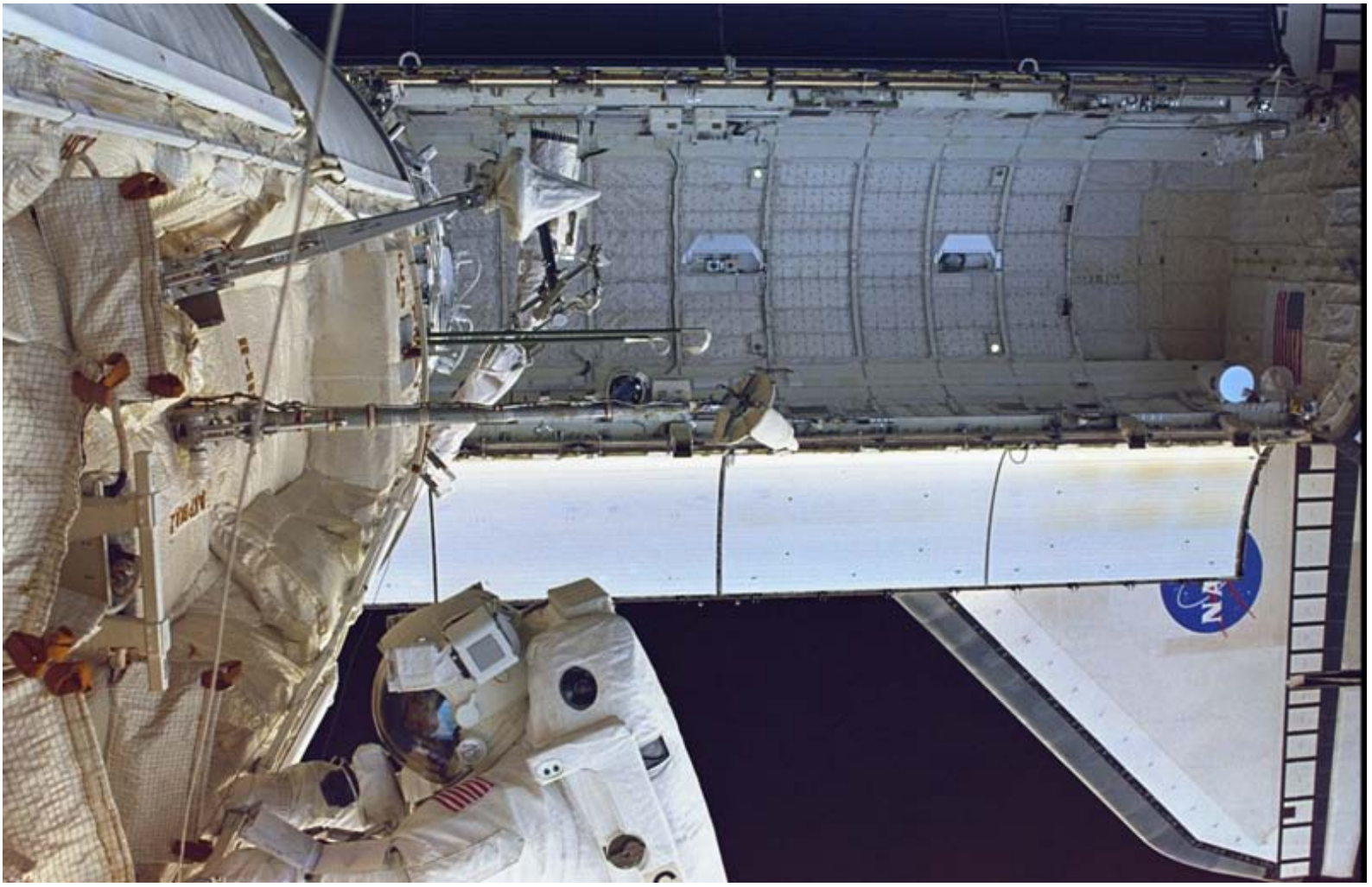

Figure 25 STS-88 EVA view fromFunctional Cargo Block (FGB) of Payload Bay while berthed to Node1/PMA2

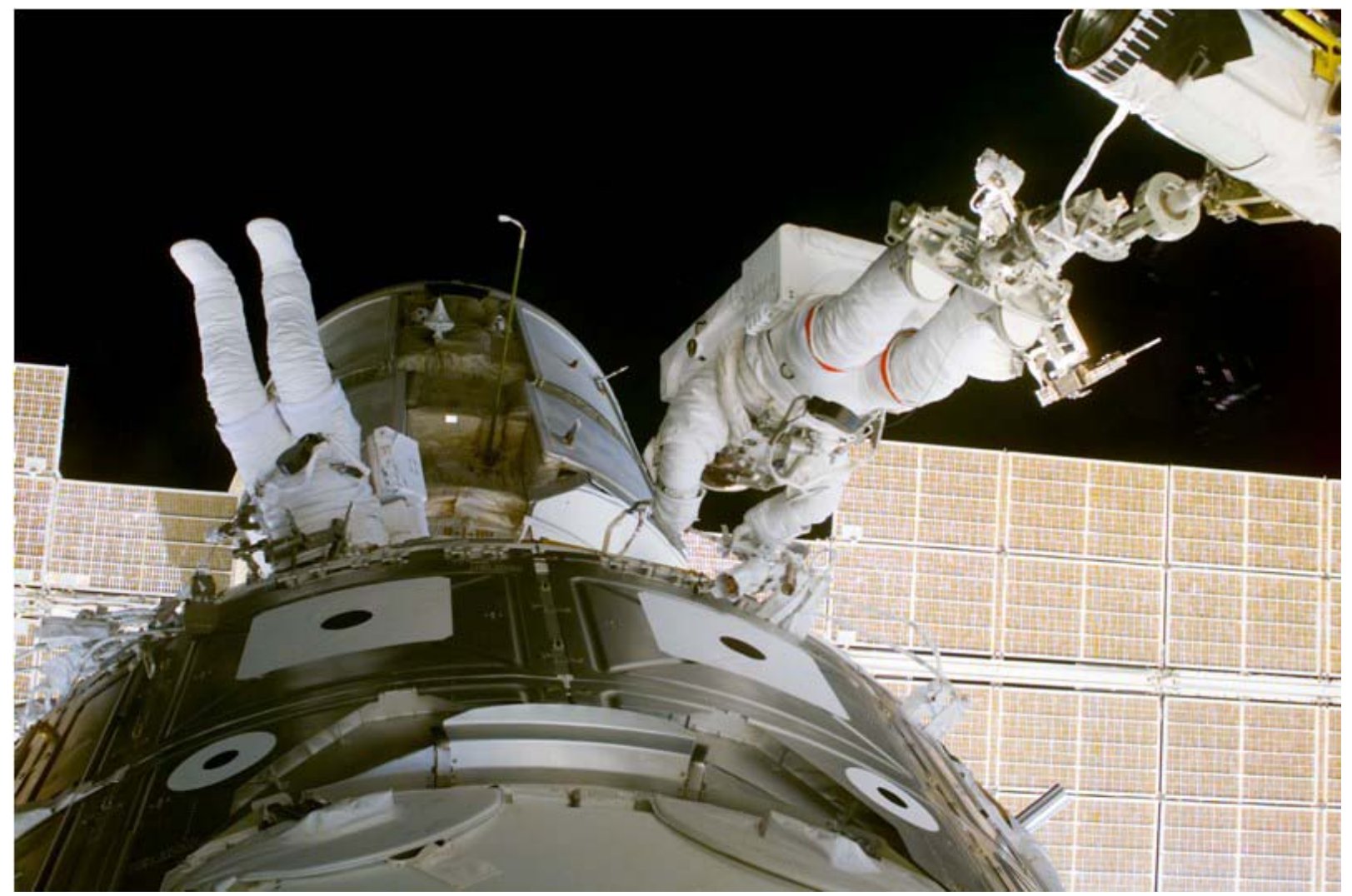

Figure 26 STS-88 View from Mid-deck as avionics connections are completed between PMA1 and Node1 


\section{EVA - Don't Leave Earth Without It}

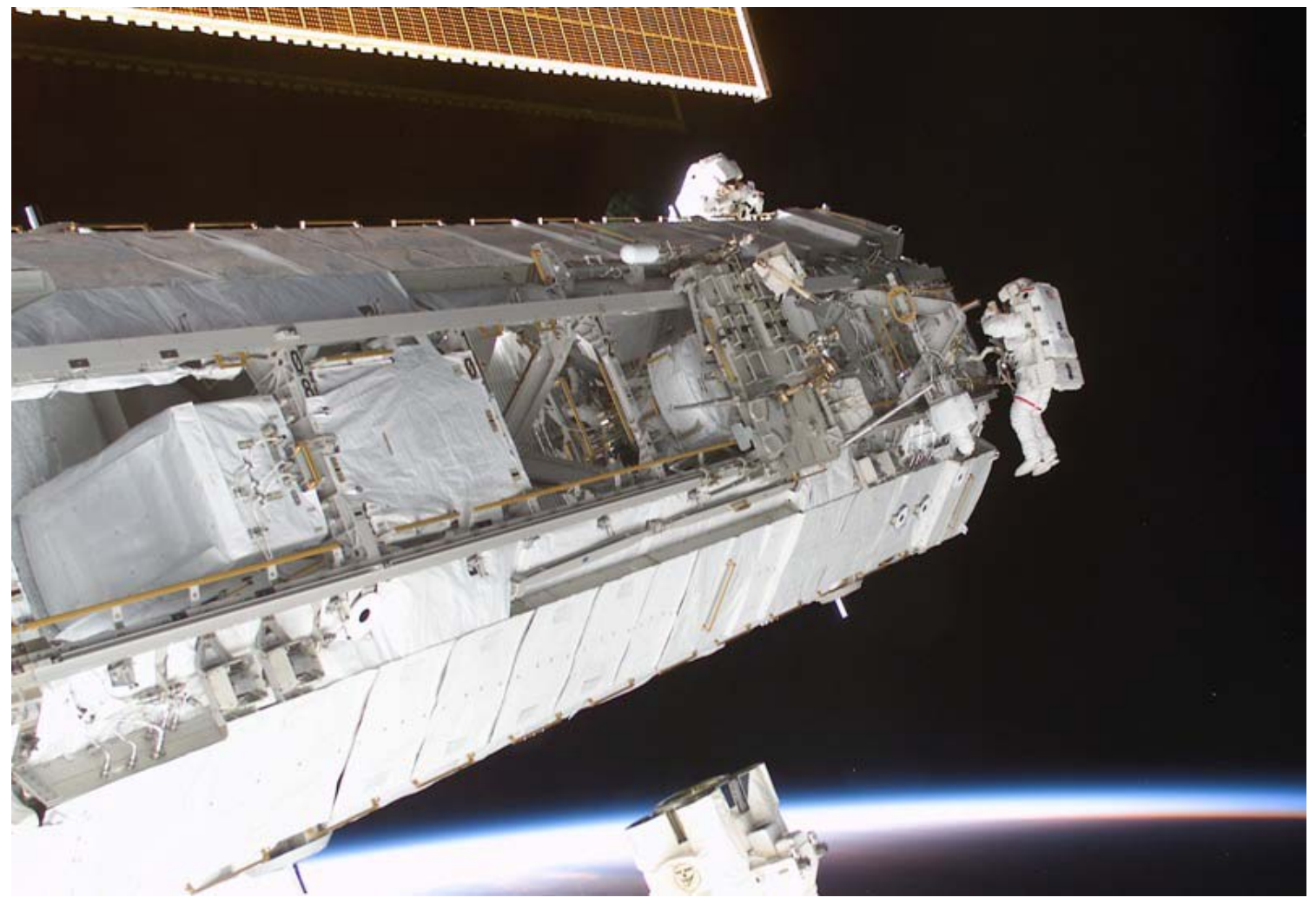

Figure 27 STS-113 EVA Crew completes assembly tasks for ISS Truss Segment P1

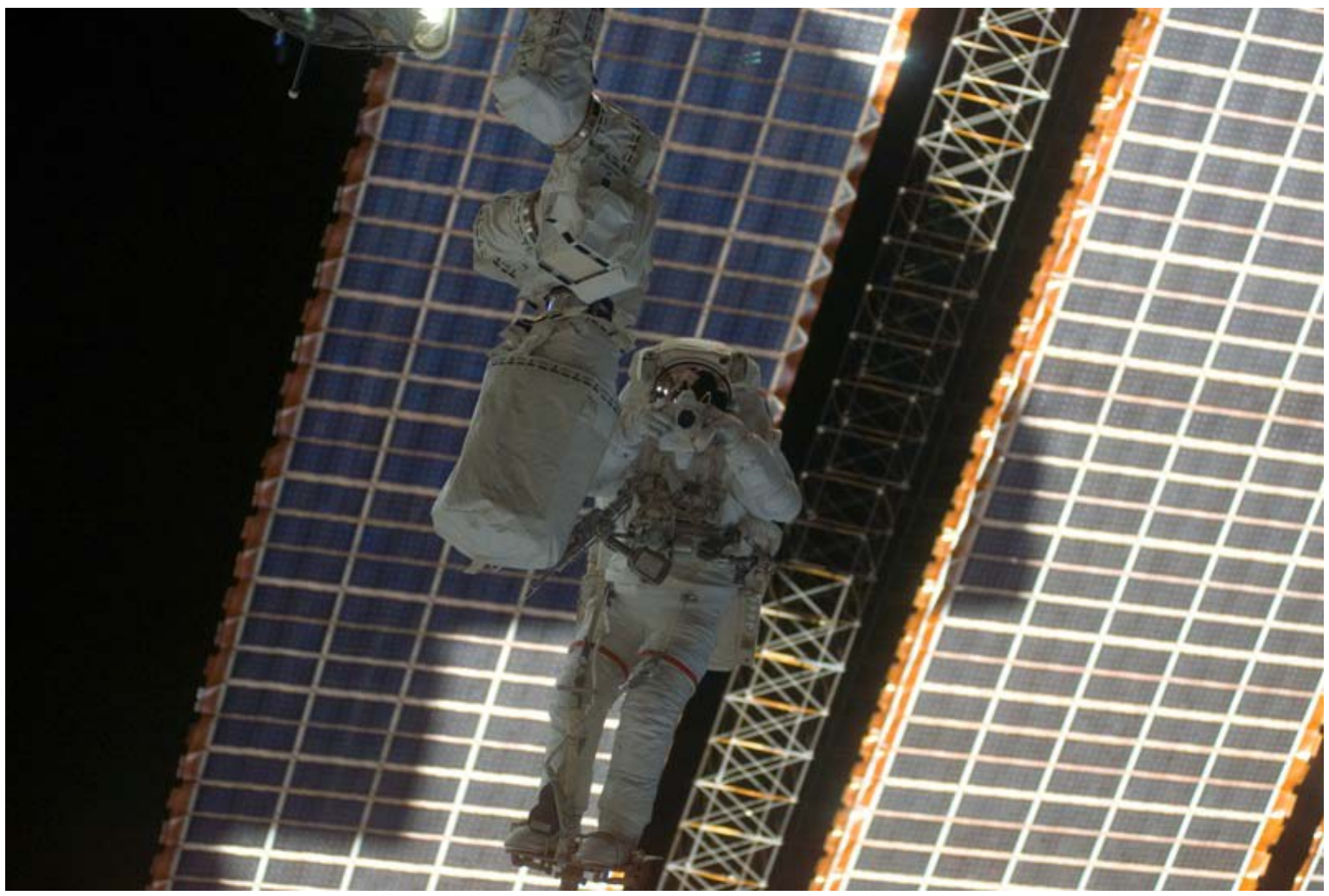

Figure 28 STS-123 Linnehan pauses from SPDM Robotic Arm assembly to take a photo of the Space Shuttle 


\section{EVA - Don't Leave Earth Without It}

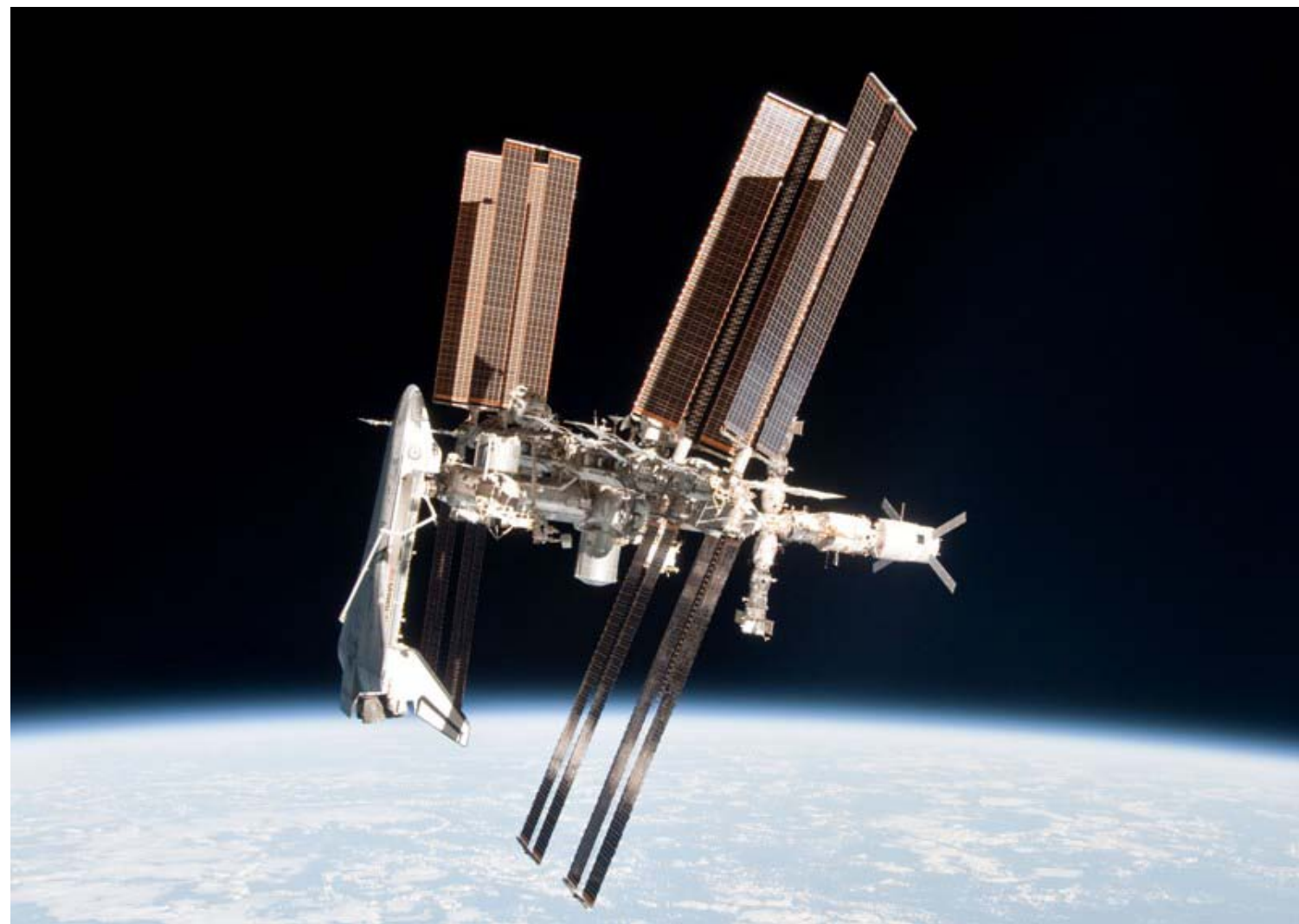

Figure 29Assembly Complete: STS-134 docked to ISS as seen from Soyuz 25S departure

\section{Space Shuttle and Space Station Repair and Maintenance}

At various times throughout the Shuttle Program, EVA has been called upon to perform maintenance tasks or restore a function of a vehicle. In a few cases, EVAs were performed to ensure survivability of a manned vehicle.

In October 1997, during the Shuttle/Mir Program, STS-86 crewmembers installed the Solar Array Cap on the Spektr module in an attempt to seal the leak created by the collision with a Progress resupply module in June of that year. Unfortunately, the cap was not able to achieve a seal, and the module remained depressurized and quarantined for the rest of the Mir mission. 


\section{EVA - Don't Leave Earth Without It}

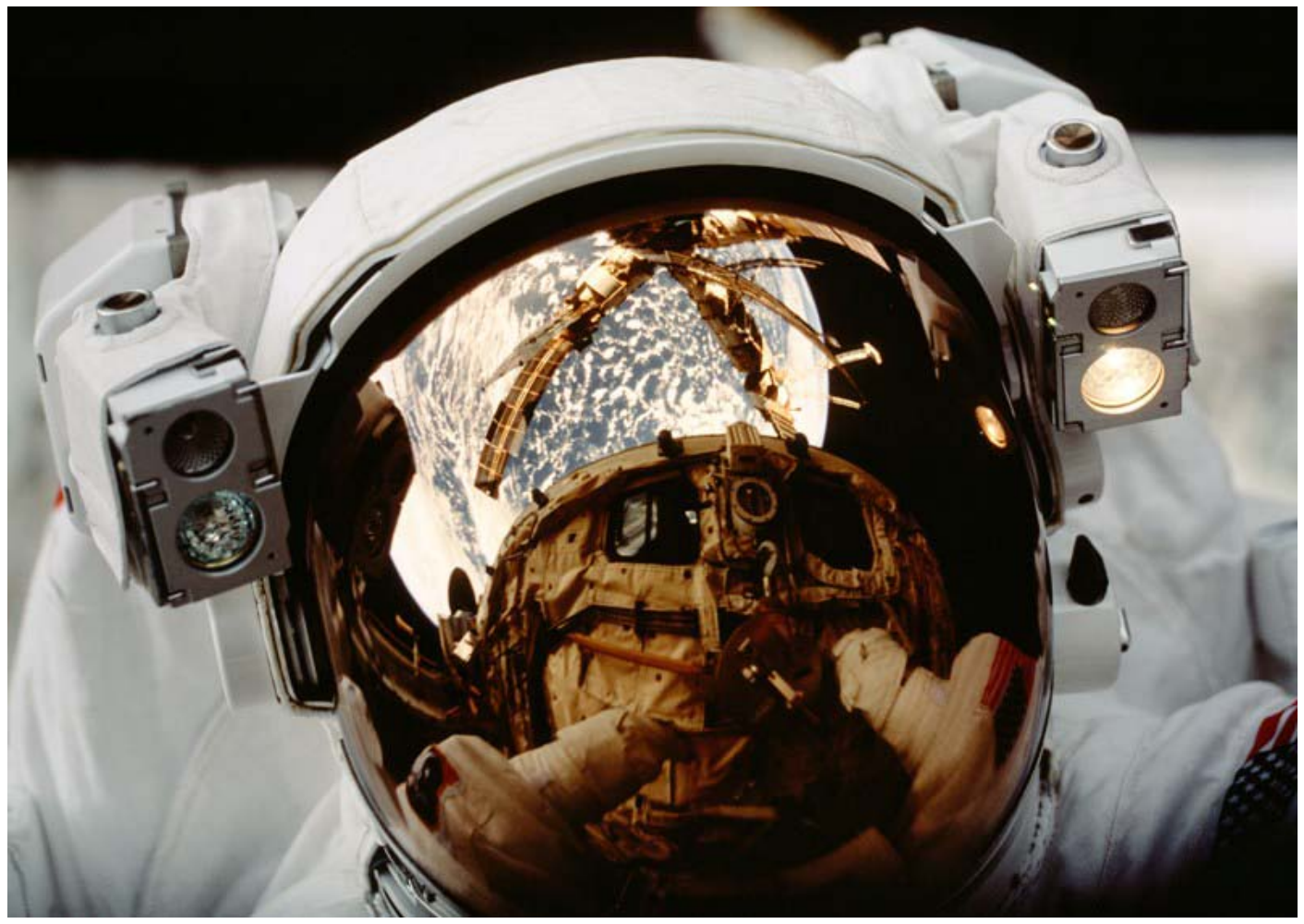

Figure 30 STS-86 Space Station Mir and docked Shuttle seen reflected in self-portrait photo

Shuttle crews also performed a significant amount of work maintaining and repairing ISS. In December 2000 during STS-97, the EVA crew inspected and repaired an ISS solar array tensioning mechanism that failed during the array's deployment. The crew adapted EVA Contingency Tools from aboard the Shuttle for the EVA, as no suitable equipment was available on ISS for the repair. This repair is one of the many examples of the value of having an adaptable EVA capability on orbit for times when tasks that no one envisioned have to be performed using techniques no one knew to develop. 


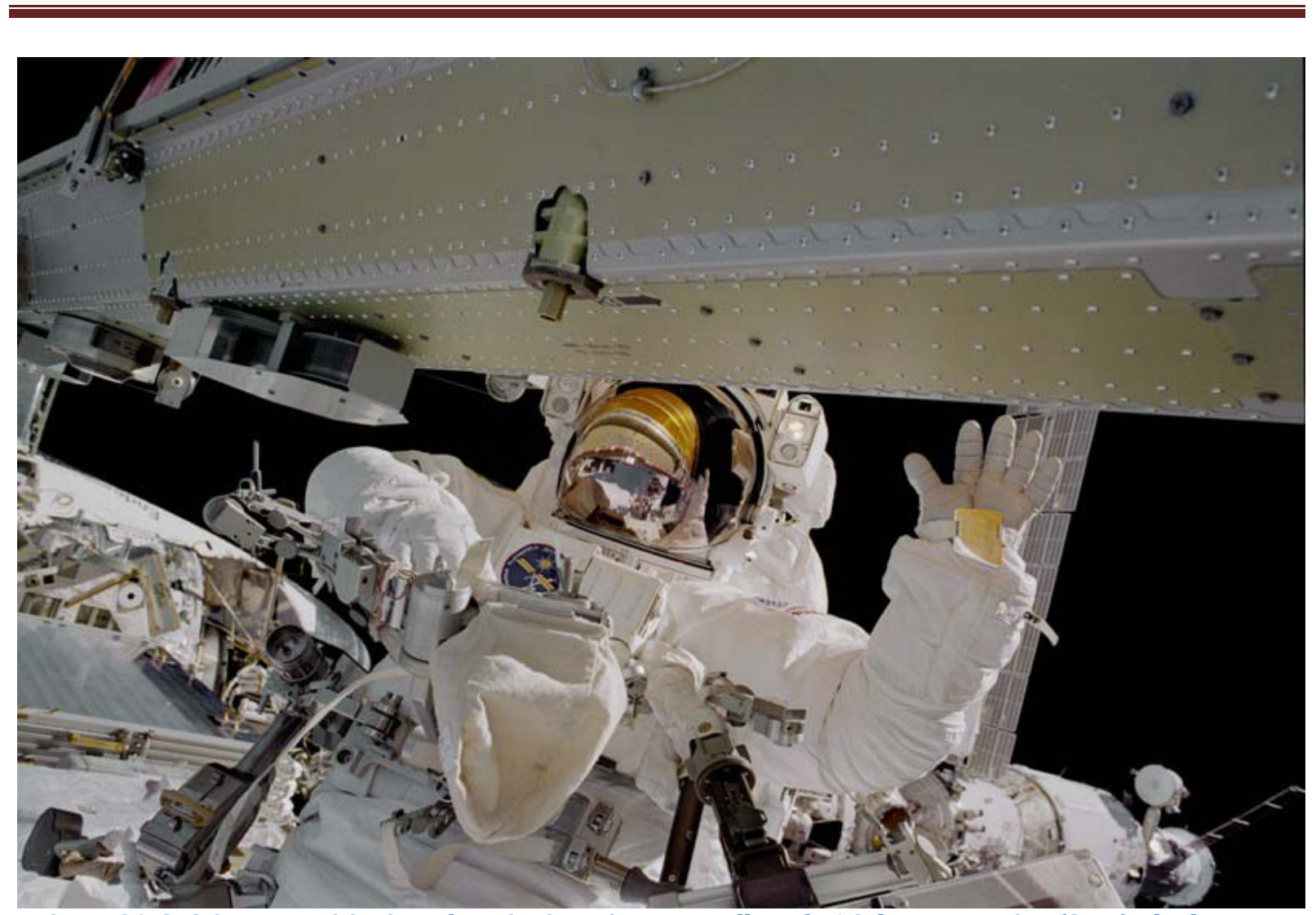

Figure 31 STS-97 Re-positioning of tensioning wire onto pulley of P6 Solar Array Wing (SAW) Blanket Box

During STS-111, the wrist joint on the SSRMS was replaced. During STS-114, both a Control Moment Gyroscope and a Global Positioning System antenna were replaced. In November 2007 during STS-120, EVA crewmembers inspected, repaired and supported the redeployment of the ISS solar array. In November 2008, during STS126, more maintenance work was performed on the ISS power generation system when the EVA crew spent four EVAs to clean debris, lubricate the solar array race ring and replace the trundle bearing of the ISS Solar Array Rotary Joints.

Following the Columbia Tragedy, NASA aggressively pursued an EVA capability to assess and repair damages to the Orbiter Thermal Protection System (TPS), including the Reinforced Carbon-Carbon (RCC) leading edge sections on the wings, the thermal tile heat shields, and blanket sections. EVA repair capability of the TPS and RCC was critical to NASA's Return To Flight effort. Without the assurance that EVA repair was possible, the Shuttle might not have flown again. The Space Shuttle TPS was inspected and repaired on two separate missions. On STS-114 in August 2005, flight controllers noticed protruding gap fillers on the forward belly of the Orbiter during the TPS inspection. A Shuttle EVA crewmember rode the Space Station Remote Manipulator System (SSRMS) to the worksite on the Orbiter to remove the questionable gap filler. On STS-117 in June 2007, EVA repairs were required for a torn and peeled thermal blanket on the port Orbital Maneuvering System pod. 
NASA has relied on EVA for repair and maintenance tasks since crewmembers deployed a sunshade and solar array on Skylab in the 1970s. The lessons derived from that experience paved the way for the EVAs of the Shuttle Programand then the Station Program, where larger and more complex tasks were performed to ensure the safety of the vehicle and the crew within it.

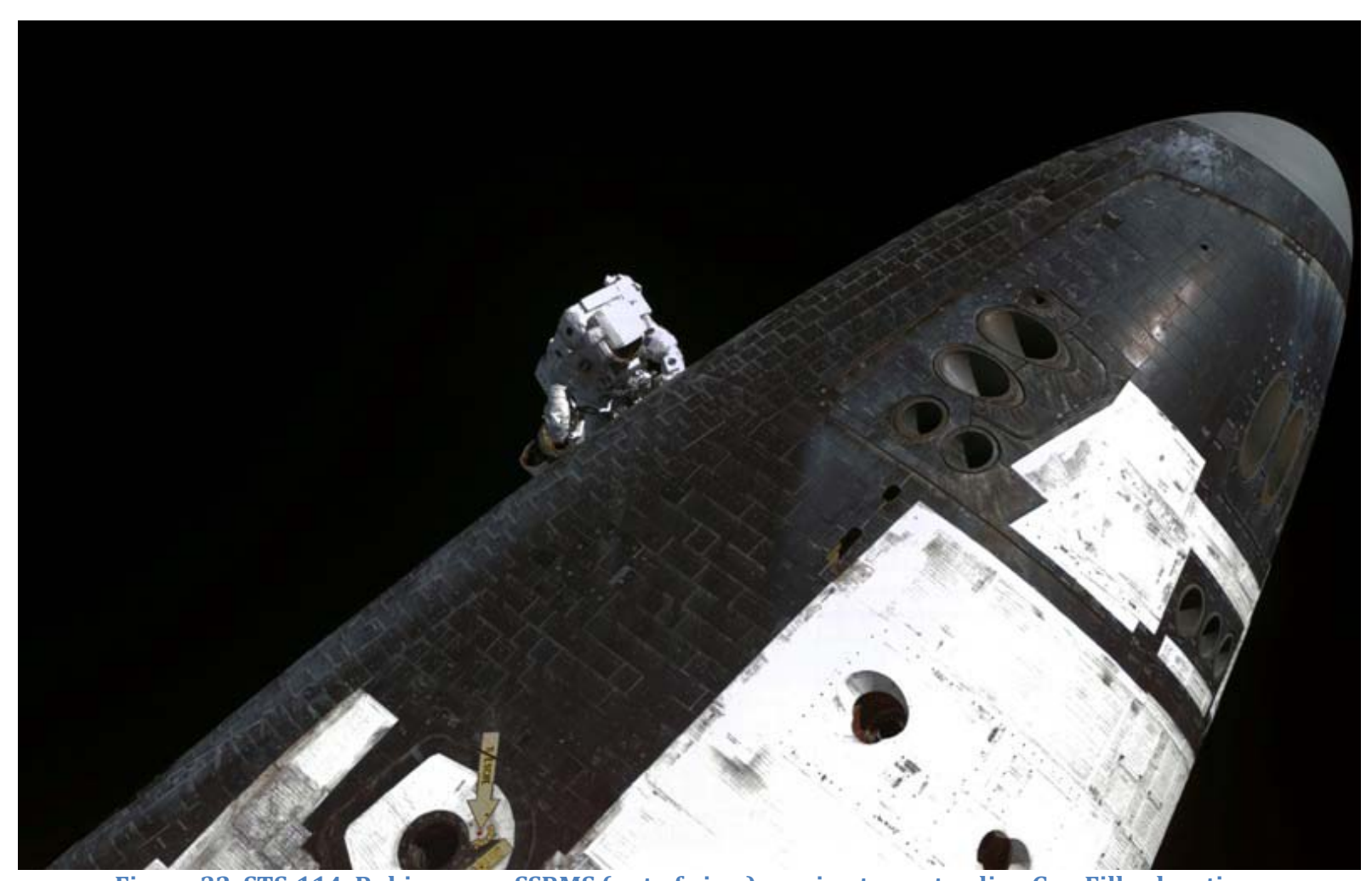

Figure 32 STS-114 Robinson on SSRMS (out of view) moving to protruding Gap Filler location 


\section{EVA - Don't Leave Earth Without It}

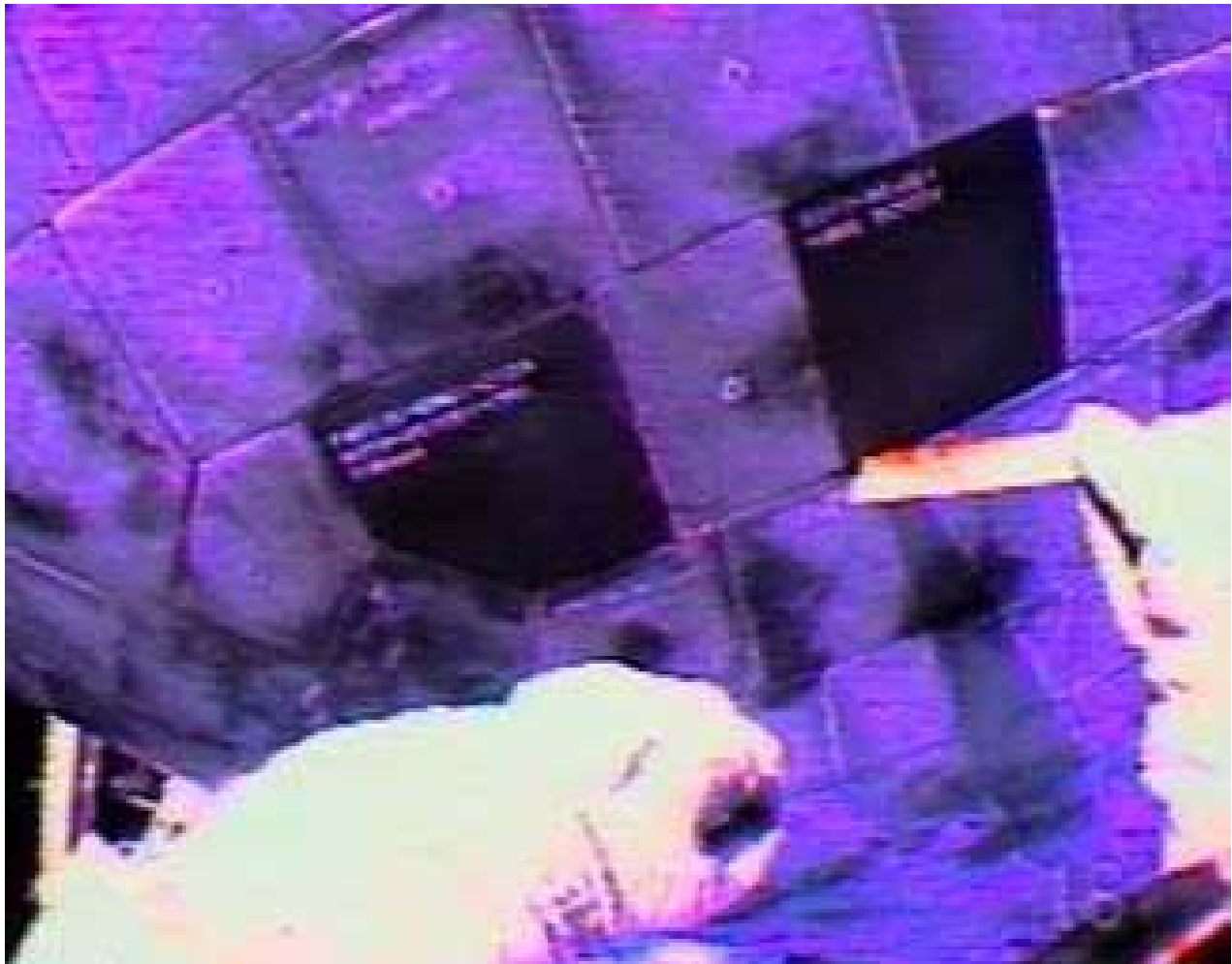

Figure 33 STS-114 EVA Gloved-hand removal of Gap Filler between heat shield tiles (Helmet-cam view)

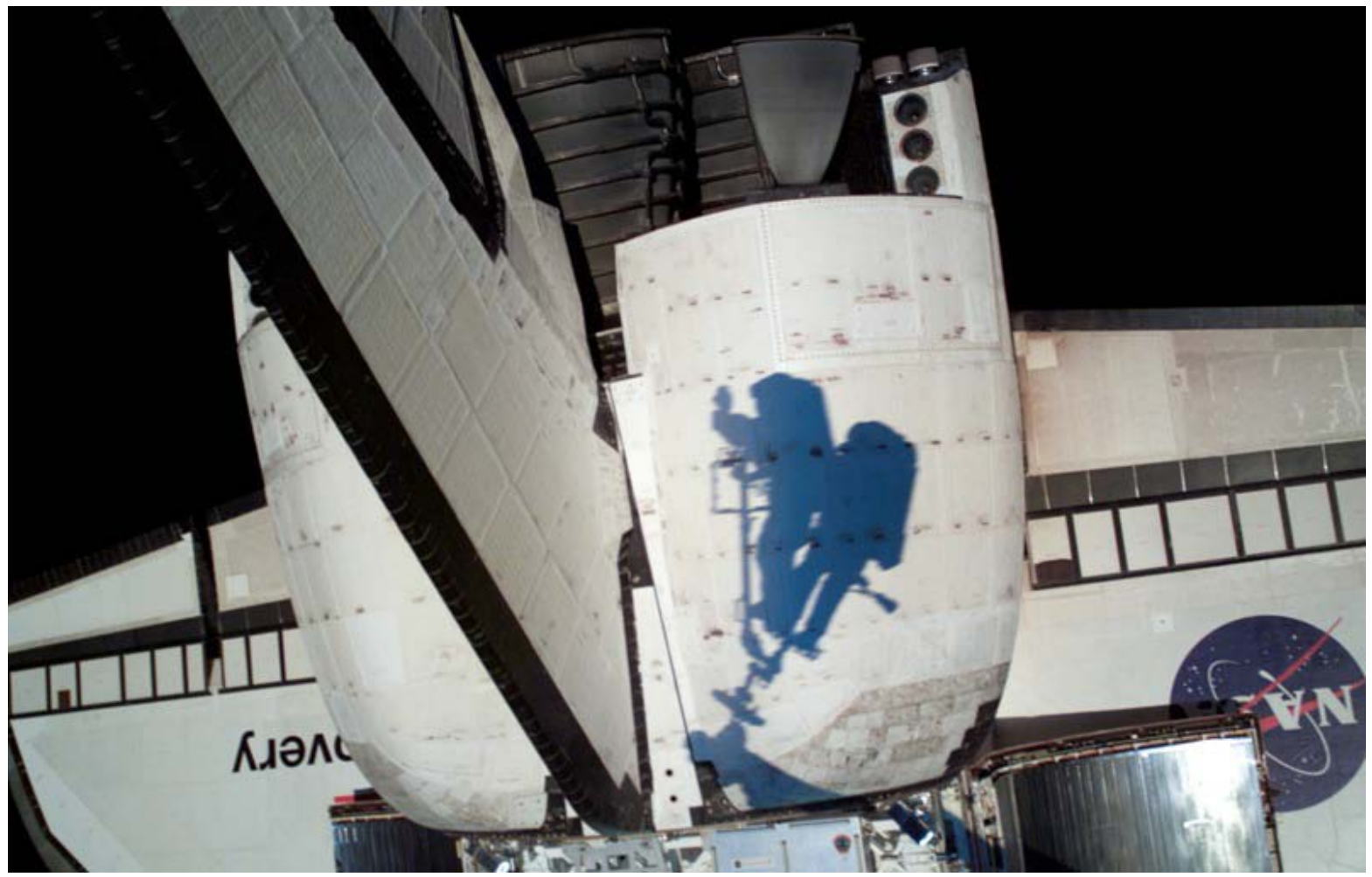

Figure 34 STS-121 Shadow from the EVA Crewmembers on end of Orbital Boom Sensor System (OBSS) 


\section{EVA - Don't Leave Earth Without It}

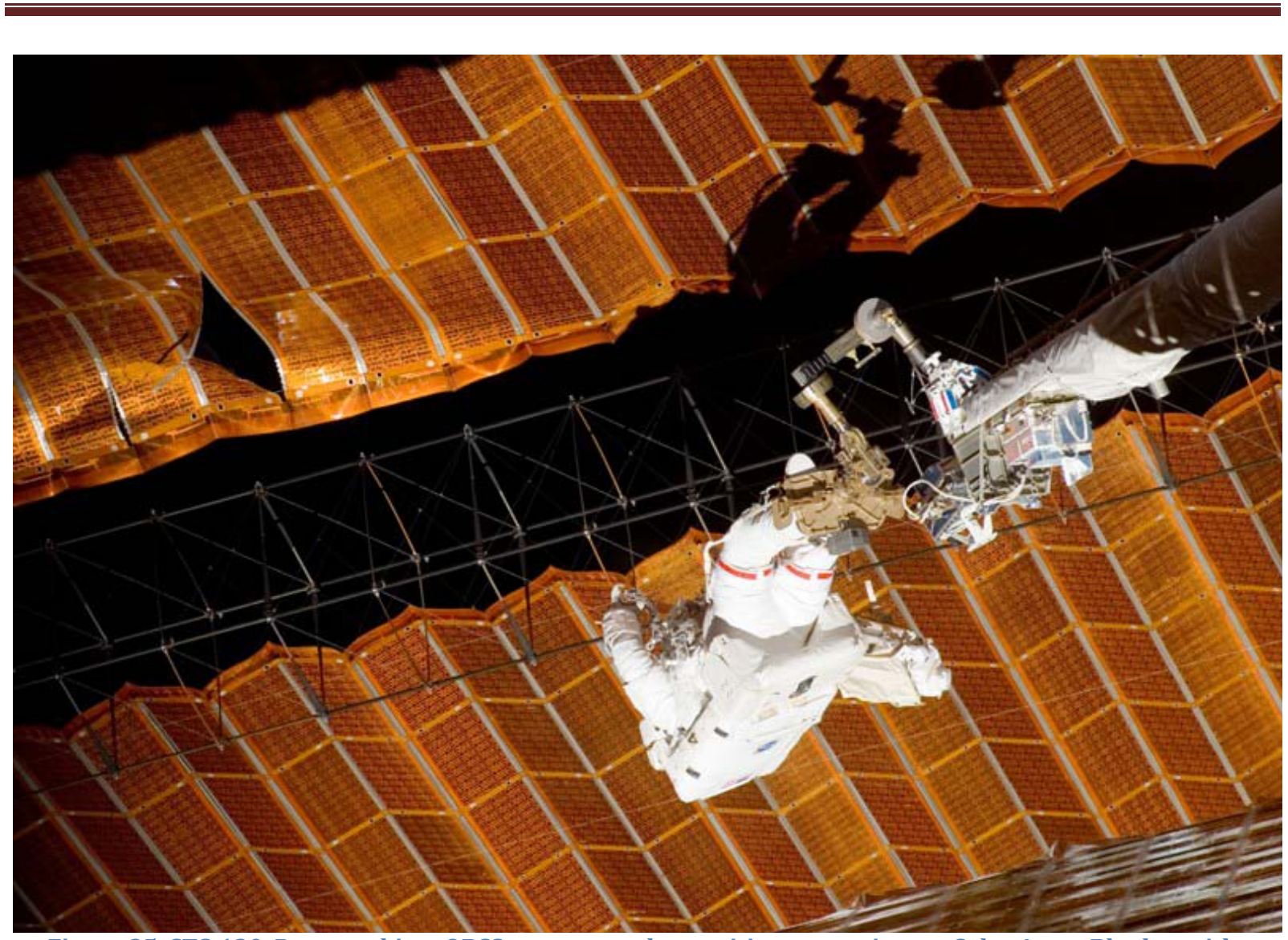

Figure 35 STS-120 Parazynski on OBSS maneuvered to position to repair torn Solar Array Blanket with improvised Cuff-links



Figure 36 STS-120 Cuff-links installed prior to Solar Array tensioning 


\section{EVA - Don't Leave Earth Without It}

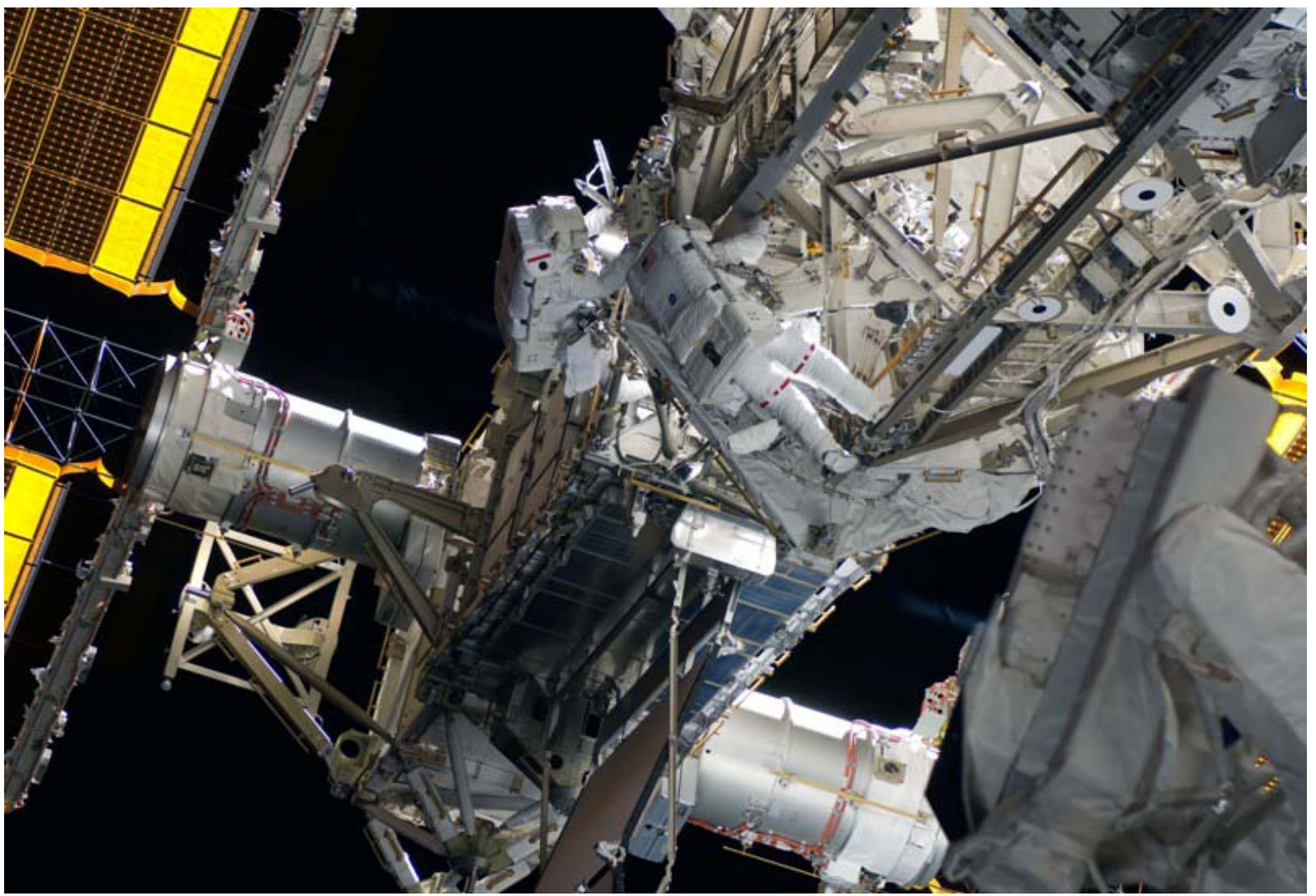

Figure 37 STS-126 EVA Crew prepares Solar Alpha Rotary Joint (SARJ) for application of lubrication on racering bearing surfaces

\section{$\underline{\text { Conclusion }}$}

EVA was not originally part of the Space Shuttle Program. However, managers soon saw the value of an EVA capability for some contingency scenarios such as shutting Payload Bay doors and closing External Tank doors. Once EVA was adopted as a core capability of the Shuttle, its true potential as an asset to NASA was realized. Of the 166 US EVAs performed during the Shuttle Program, 144 of them were dedicated to inspecting, retrieving, maintaining, repairing or rescuing a spacecraft in some manner or other.

EVA holds significant, unique advantages over other methods of working in the space environment. EVA crewmembers can provide real-time feedback on worksite conditions and problems being encountered. EVA crewmembers have provided solutions to problems such as stuck bolts and jammed hinges that would have otherwise been impossible for robots to solve. EVA crewmembers have improvised procedures and adapted tools to deploy stuck antennas and furl solar arrays that used mechanisms that were never expected to fail.

One important legacy of the Shuttle Program is that EVA was successfully employed to achieve national, program and mission goals. Managers, engineers and designers of future spacecraft systems would do well to remember this EVA legacy. 


\section{$\underline{\text { References }}$}

Johnson, Kieth G. (2011). EVA History File. Retrieved August 19, 2011, from https://modspops.jsc.nasa.gov/mod/dx/DX32\%20DX35\%20SharePoint/default.aspx

JSC Imagery Online. (2011). Retrieved August 19, 2011, from

http://io.jsc.nasa.gov/app/index.cfm

Portree, David S. F. and Trevino, Robert C. (1997). Walking to Olympus: An EVA Chronology(Monographs in Aerospace History Series \#7). Washington, DC: NASA History Office.

Shuttle Program photographic archive (2011). Retrieved August $8^{\text {th }}$, from http://science.ksc.nasa.gov/mirrors/images/html/shuttle.htm

Space Shuttle Mission Information (2011). Retrieved August 5, 2011, from http://www.nasa.gov/mission pages/shuttle/shuttlemissions/index.html

Thomas, Kenneth S. and McMann, Harold J. ((2006), US Spacesuits. Chichester, UK: Praxis 